\title{
Hypoxia Silences Retrotrapezoid Nucleus Respiratory Chemoreceptors via Alkalosis
}

\author{
Tyler M. Basting, ${ }^{1 \star}$ Peter G.R. Burke, ${ }^{1 \star}$ Roy Kanbar, ${ }^{2}$ Kenneth E. Viar, ${ }^{1}$ Daniel S. Stornetta, ${ }^{1}$ Ruth L. Stornetta, ${ }^{1}$ \\ and Patrice G. Guyenet ${ }^{1}$ \\ ${ }^{1}$ Department of Pharmacology, University of Virginia, Charlottesville, Virginia 22908, and ${ }^{2}$ Department of Pharmaceutical Sciences, Lebanese American \\ University, Beyrouth, Lebanon
}

In conscious mammals, hypoxia or hypercapnia stimulates breathing while theoretically exerting opposite effects on central respiratory chemoreceptors (CRCs). We tested this theory by examining how hypoxia and hypercapnia change the activity of the retrotrapezoid nucleus (RTN), a putative CRC and chemoreflex integrator. Archaerhodopsin-(Arch)-transduced RTN neurons were reversibly silenced by light in anesthetized rats. We bilaterally transduced RTN and nearby C1 neurons with Arch (PRSx8-ArchT-EYFP-LVV) and measured the cardiorespiratory consequences of Arch activation (10 s) in conscious rats during normoxia, hypoxia, or hyperoxia. RTN photoinhibition reduced breathing equally during non-REM sleep and quiet wake. Compared with normoxia, the breathing frequency reduction $\left(\Delta \mathrm{f}_{\mathrm{R}}\right)$ was larger in hyperoxia $\left(65 \% \mathrm{FiO}_{2}\right)$, smaller in $15 \% \mathrm{FiO}_{2}$, and absent in $12 \% \mathrm{FiO}_{2}$. Tidal volume changes $\left(\Delta \mathrm{V}_{\mathrm{T}}\right)$ followed the same trend. The effect of hypoxia on $\Delta \mathrm{f}_{\mathrm{R}}$ was not arousal-dependent but was reversed by reacidifying the blood $\left(\right.$ acetazolamide; $3 \%$ FiCO $\left.{ }_{2}\right) . \Delta \mathrm{f}_{\mathrm{R}}$ was highly correlated with arterial $\mathrm{pH}$ up to arterial $\mathrm{pH}$ ( $\mathrm{pHa}$ ) 7.5 with no frequency inhibition occurring above $\mathrm{pHa} 7.53$. Blood pressure was minimally reduced suggesting that $\mathrm{C} 1$ neurons were very modestly inhibited. In conclusion, RTN neurons regulate eupneic breathing about equally during both sleep and wake. RTN neurons are the first putative CRCs demonstrably silenced by hypocapnic hypoxia in conscious mammals. RTN neurons are silent above pHa 7.5 and increasingly active below this value. During hyperoxia, RTN activation maintains breathing despite the inactivity of the carotid bodies. Finally, during hypocapnic hypoxia, carotid body stimulation increases breathing frequency via pathways that bypass RTN.

Key words: Archaerhodopsin; chemoreflex; medulla oblongata; optogenetics; Phox2b; ventrolateral medulla

\section{Introduction}

Feedback regulation of breathing by $\mathrm{CO}_{2}$ and $\mathrm{O}_{2}$ operates via the carotid bodies (CBs), which respond to hypoxia in an aciddependent manner and via central respiratory chemoreceptors (CRCs) that detect brain $\mathrm{PCO}_{2} / \mathrm{pH}$ (Takakura et al., 2006; Guyenet et al., 2010; Smith et al., 2010; Huckstepp and Dale, 2011; Kumar and Prabhakar, 2012). Usually, CBs and CRCs work in concert to either stimulate or inhibit breathing because arterial $\mathrm{PO}_{2}$ and brain $\mathrm{PCO}_{2}$ vary in opposite directions when lung ventilation changes. In a hypoxic environment, however, the CBs are selectively activated and the resulting hyperventilation causes respiratory alkalosis and CRCs are thought to be inhibited (Gesell et al., 1940). In reality, however, no CRC candidate (e.g., astrocytes, retrotrapezoid nucleus [RTN], serotonergic, orexinergic, and/or locus ceruleus neurons) has ever been shown to be inhib-

Received July 17, 2014; revised Nov. 5, 2014; accepted Nov. 12, 2014.

Author contributions: T.M.B., P.G.R.B., R.K., R.L.S., and P.G.G. designed research; T.M.B., P.G.R.B., R.K., K.E.V., D.S.S., R.L.S., and P.G.G. performed research; T.M.B., P.G.R.B., R.K., R.L.S., and P.G.G. analyzed data; T.M.B., P.G.R.B., R.L.S., and P.G.G. wrote the paper.

This work was supported by National Institutes of Health Grants HL28785 and HL74011 to P.G.G.

The authors declare no competing financial interests.

*T.M.B. and P.G.R.B. contributed equally to this work.

Correspondence should be addressed to Dr. Patrice G. Guyenet, University of Virginia Health System, P.O. Box 800735, 1300 Jefferson Park Avenue, Charlottesville, VA 22908-0735. E-mail: pgg@virginia.edu.

DOI:10.1523/JNEUROSCI.2923-14.2015

Copyright $\odot 2015$ the authors $\quad 0270-6474 / 15 / 350527-17 \$ 15.00 / 0$ ited by hypocapnic hypoxia. Hypocapnic hypoxia commonly produces sleep-disrupted breathing, a condition that improves with $\mathrm{CO}_{2}$ supplementation or acetazolamide administration (Peña and García, 2006; Bell and Haouzi, 2010; Ainslie et al., 2013; Javaheri and Dempsey, 2013).

Hyperoxia, widely used therapeutically, reduces CB activity, which causes an immediate but transient breathing reduction (Dejours et al., 1955). At steady state, hyperoxia causes a small hypoventilation in rodents or slight hyperventilation in humans, the latter being tentatively attributed to excess CRC activation via cerebral blood flow reduction and other mechanisms (Olson et al., 1988; Becker et al., 1996; Ainslie and Duffin, 2009; Chowdhuri et al., 2010). The notion that CRCs are activated by hyperoxia also remains unsubstantiated.

RTN is a prominent CRC candidate (Smith et al., 1989; Guyenet et al., 2010; Nattie, 2011). Although RTN neurons are intrinsically $\mathrm{pH}$-sensitive, they also respond to acidification via surrounding astrocytes and receive synaptic inputs from additional presumptive CRCs (Mulkey et al., 2004; Gourine et al., 2010; Wang et al., 2013a, b). RTN innervates the respiratory pattern generator, and its selective stimulation activates breathing massively (Abbott et al., 2009b, 2011). RTN therefore may operate both as a CRC and central respiratory chemoreflex integrator.

The present experiments had three objectives: (1) to determine whether RTN regulates breathing at rest; (2) to test whether 
RTN neurons are silenced during hypocapnic hypoxia in conscious rats (i.e., whether RTN conforms to existing predictions regarding how CRCs should behave under hypoxic conditions); and (3) to determine how RTN neurons regulate breathing during hyperoxia. RTN neurons are located close to the ventral medullary surface and are thinly distributed (Stornetta et al., 2006), which precludes unit recording in conscious animals. Fos can be used to gauge RTN activity, but this approach is insensitive and restricted to long-lasting perturbations (Sato et al., 1992; Teppema et al., 1997; Fortuna et al., 2009). To assess RTN neuron activity, we monitored the degree of hypoventilation elicited by briefly inhibiting these neurons using Archaerhodopsin (Arch)based optogenetics (Chow et al., 2010). This method allowed us to quantify the instantaneous contribution of RTN neurons to ventilation with minimal interference from homeostatic regulations because of the slow time constant of the chemoreflexes.

\section{Materials and Methods}

Animals. Experiments were performed on male Sprague Dawley rats $(N=27 ; 400-550 \mathrm{~g}$, Taconic). All procedures conformed to the National Institutes of Health Guide for the Care and Use of Laboratory Animals and were approved by the University of Virginia Animal Care and Use Committee. Animals were housed under standard $12 \mathrm{~h}$ light/dark cycle with ad libitum access to food and water.

Viral constructs and virus preparation. For single-unit experiments in anesthetized rats, we used an adeno-associated viral vector (AAV) that expresses the photoactivatable proton pump Arch-3 fused to EYFP under the control of the pan-neuronal synapsin promoter (AAV-hSyneArch3.0-EYFP serotype 2) (Chow et al., 2010). For the experiments on conscious rats, we used a lentiviral vector (LVV) that expresses ArchT3.0, a more light-sensitive version of Arch-3 (Han et al., 2011; Mattis et al., 2012) under the Phox2-responsive promoter PRSx8 (pLenti-PRSX8 eArchT3.0-EYFP) (Hwang et al., 2001). We synthesized the PRSx8ArchT3.0-EYFP construct by substituting the PRSx8 promoter (kindly provided by M. Raizada, University of Florida, Gainesville, Florida) for the CaMKII $\alpha$ promoter present in the pLenti CaMKII $\alpha$ eArchT 3.0 EYFP construct (courtesy of K. Deisseroth via Addgene). In a few experiments on conscious rats, we also used an already described LVV encoding the photoactivatable cation channel channelrhodopsin-2 (ChR2, H134R) fused to mCherry (PRSx8-ChR2-mCherry) (Abbott et al., 2009a, b). Viral vectors (AAV2 and LVV) were produced by the University of North Carolina virus core. The AAV2 was used at a concentration of $3.0 \times 10^{12}$ viral particles per milliliter. Both LVVs were used at a concentration of $3.0 \times 10^{8}$ viral particles per milliliter.

Injections of vectors and animal instrumentation. Rats were anesthetized with a mixture of ketamine $(75 \mathrm{mg} / \mathrm{kg})$, xylazine $(5 \mathrm{mg} / \mathrm{kg})$, and acepromazine $(1 \mathrm{mg} / \mathrm{kg})$ given intraperitoneally. Depth of anesthesia was assessed by an absence of the corneal and hind-paw withdrawal reflexes. Additional anesthetic was administered when necessary ( $25 \%$ of the original dose, i.p. or i.m. during surgery). Body temperature was kept close to $37^{\circ} \mathrm{C}$ with a servo-controlled heating pad and a blanket. All surgical procedures were performed under aseptic conditions.

The vectors were injected into RTN using electrophysiological landmarks as follows. The mandibular branch of the facial nerve was exposed on the left side or on both sides as needed. The rat was then placed prone on a stereotaxic apparatus (bite bar set at $-3.0 \mathrm{~mm}$ for flat skull; David Kopf Instruments). A 1.5-mm-diameter hole was drilled into the occipital plate on the left side or both sides caudal to the parieto-occipital suture. Viral vectors were loaded into a $1.2 \mathrm{~mm}$ internal diameter glass pipette broken to a $25 \mu \mathrm{m}$ tip (external diameter). The lower edge of the facial motor nucleus was identified using antidromic field potentials evoked by facial nerve stimulation $(0.1 \mathrm{~ms}, 0.2-0.8 \mathrm{~mA}$ ) (Brown and Guyenet, 1985), and the vector was ejected by pressure $100-200 \mu \mathrm{m}$ below this level where RTN neurons reside.

ArchT3.0 LVV was injected bilaterally into three rostrocaudally aligned sites separated by $200 \mu \mathrm{m}$ (total volume $400-600 \mathrm{nl} / \mathrm{side}$ ). Mean stereotaxic coordinates were $2.1-2.7 \mathrm{~mm}$ caudal to lambda, $2 \mathrm{~mm}$ lateral to the midline, and $8.6 \mathrm{~mm}$ below the cerebellar surface. The most caudal site was located under the caudal end of the facial motor nucleus. We then implanted optical fibers for light stimulation plus electrodes to record the EEG and neck EMG. For EEG recordings, stainless steel jeweler screws (Plastics One) were implanted extradurally $(0.5-1 \mathrm{~mm}$ anterior, $1 \mathrm{~mm}$ lateral to bregma and $3 \mathrm{~mm}$ posterior, $2-2.5 \mathrm{~mm}$ lateral to bregma above the contralateral hemisphere). One additional screw was implanted for structural support of the head stage and for grounding. Teflon-coated braided stainless steel wire (A-M Systems) was stripped at the tip and wrapped around the implanted screws. Two additional wires were stripped at the tips and implanted in the superficial muscles of the neck for EMG recordings of postural activity. All wires were crimped to amphenol pins (A-M Systems) and inserted into a plastic head stage (Plastics One). Optical fibers (200 $\mu \mathrm{m}$, numerical aperture-0.39; Thorlabs) were fitted with ferrules as described previously (Sparta et al., 2012) and implanted into the ventrolateral medulla (tips $0.5-0.8 \mathrm{~mm}$ dorsal to the vector injection site). The head stage and optic fiber-ferrule assemblies were secured to the skull using a two part epoxy (Loctite). Incisions were then closed in two layers (muscle and skin) with absorbable sutures and vet bond adhesive. Rats received postoperative ampicillin $(125 \mathrm{mg} /$ $\mathrm{kg}$, i.p.) and ketoprofen (3-5 mg/kg, subcutaneously) and were monitored daily. Rats recovered for a minimum of 4 weeks for functional expression of the opsins. A subset of animals were then implanted with radio-telemetry probes (PA-C10, Data Sciences International) to record blood pressure (BP) from the descending aorta via the right femoral artery. These rats recovered for yet another week before physiological experiments began. A second cohort of rats $(N=6)$ were catheterized for arterial blood gas measurements in conscious whole-body plethysmography (for detailed methods, see Jespersen et al., 2012).

In six rats, ChR2-expressing LVV was injected unilaterally on the left side (two $100-140 \mathrm{nl}$ injections separated by $200 \mu \mathrm{m}$ ). These rats were then instrumented in the same way as those that had received injections of ArchT-expressing vector (EMG, EEG, fiber optic), except that a single optical fiber was implanted, on the left side. Four rats received a left side only injection of AAV2-hSyn-eArch3.0-EYFP into RTN (two 100-140 nl injections separated by $200 \mu \mathrm{m}$ ). These rats had no additional surgical procedure. Postsurgical treatment for these two groups was as described above.

RTN unit recordings in anesthetized rats. These experiments were designed to ascertain that Arch-transduced RTN neurons were inhibited by $532 \mathrm{~nm}$ wavelength (green) light from a laser delivered through an optical fiber in vivo in their vicinity. These optogenetic experiments were modeled after prior ones in which we tested the light sensitivity of ChR2transduced RTN neurons (Abbott et al., 2009b). Briefly, 4 rats received injections of AAV-hSyn-eArch3.0-EYFP serotype 2 into the left RTN. Five weeks later, rats were anesthetized with isoflurane (5\% for induction, $3 \%$ thereafter) in $100 \%$ oxygen, the trachea was cannulated to permit artificial ventilation, and one femoral artery and vein were cannulated to record arterial BP and administer fluids, respectively. RTN units were recorded below the facial motor nucleus as described previously (Guyenet et al., 2005). A $200 \mu \mathrm{m}$ optical fiber was inserted at a 20 degree angle from the vertical in the transverse plane and its tip placed an estimated $500 \mu \mathrm{m}$ above the left RTN. The light output at the tip of the fiber optic was adjusted to $9 \mathrm{~mW}$ with a light meter (Thorlabs) before insertion into the brain. Upon completion of surgical procedures, isoflurane was gradually withdrawn while freshly prepared $\alpha$-chloralose (dissolved in $2 \% \mathrm{Na}$ borate; initial dose of $60 \mathrm{mg} / \mathrm{kg}$; maintenance at 30 $\mathrm{mg} / \mathrm{kg} / \mathrm{h}$ ) and urethane (10\% weight by volume in physiological saline; initial dose: $0.7 \mathrm{~g} / \mathrm{kg}$ ) were slowly infused intravenously, and ventilation with $100 \% \mathrm{O}_{2}$ was continued. The adequacy of the anesthesia was assessed by the lack of arterial pressure change and limb withdrawal following a firm paw pinch. Paralysis was induced with vecuronium bromide before the recordings (induction dose $0.1 \mathrm{mg} / \mathrm{kg}$, i.v., plus additional $0.05 \mathrm{mg} / \mathrm{kg} / \mathrm{h}$ infusion for maintenance). End-expiratory $\mathrm{CO}_{2}$ $\left(\right.$ eeCO $\left.\mathrm{C}_{2}\right)$ was continuously monitored with a micro-capnometer (Columbus Instruments) and maintained between 3.5\% and 4.5\%. Neurons were recorded extracellularly using glass pipettes filled with $2 \mathrm{M} \mathrm{NaCl}$ $(5-10 \mathrm{M} \Omega)$. RTN neurons were characterized as described previously (Guyenet et al., 2005). Their $\mathrm{CO}_{2}$ sensitivity was determined by adding 

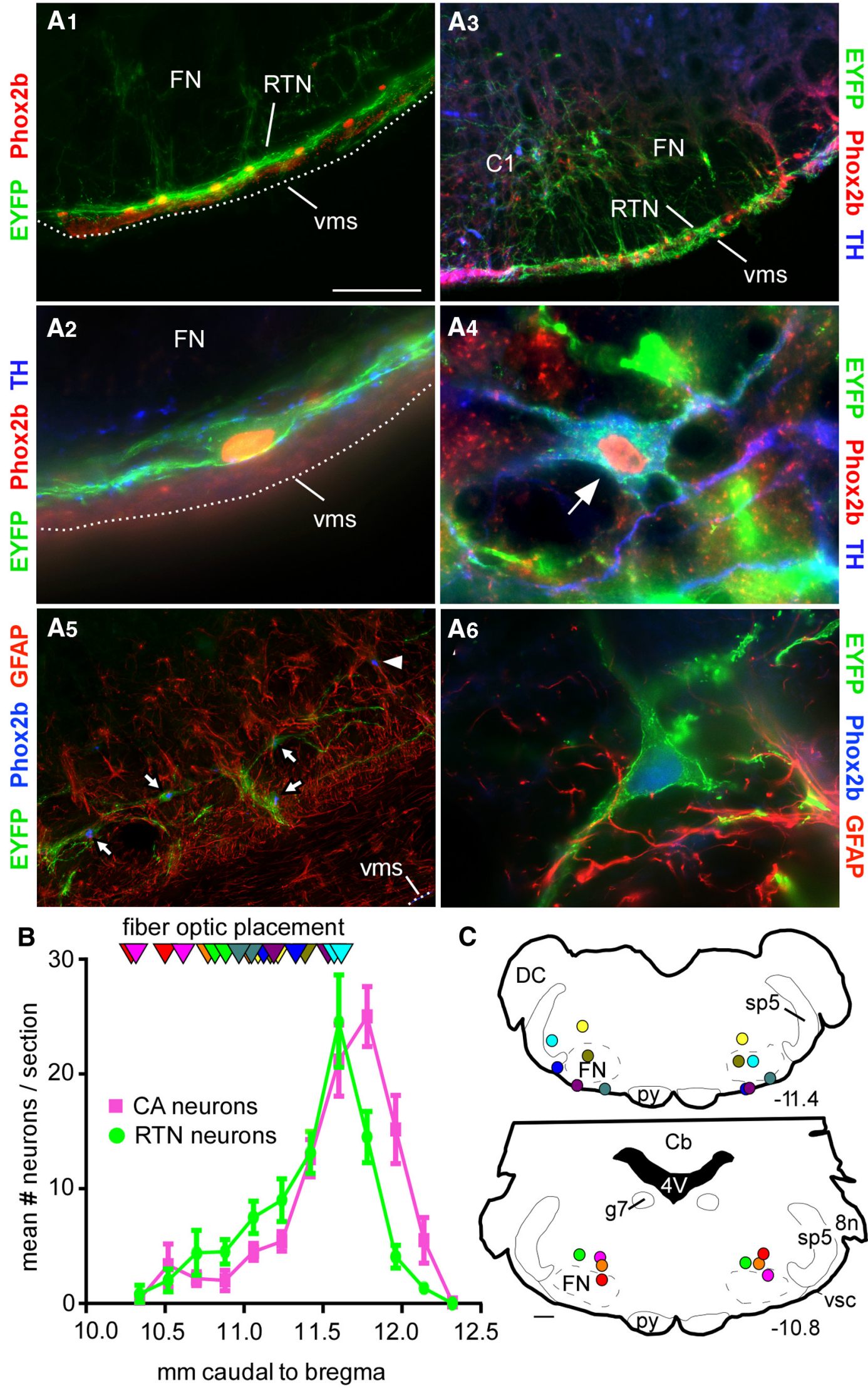

Figure 1. Location of Arch-transduced neurons and fiber optic tips. $A_{1}$, Coronal section through the medulla (level $\sim 11.4 \mathrm{~mm}$ caudal to bregma) illustrating the selective expression of ArchT-EYFP by RTN neurons. RTN is identified by the line of strongly Phox2b-ir nuclei close to the ventral medullary surface (Takakura et al., 2006). $\boldsymbol{A}_{2}$, Higher-power photograph of an ArchTtransduced RTN neuron. This neuron had a Phox2b-immunoreactive (ir) nucleus, was negative for TH, but had close appositions from TH-ir synaptic boutons. $A_{3}$, Coronal section (level $\sim 11.7$ mm caudal to bregma) showing transduced RTN neurons (on the ventral medullary surface) and catecholamine (CA, presumably $(1)$ cells dorsal to the latter. $\boldsymbol{A}_{\mathbf{4}^{\prime}}$ (Figure legend continues.) 
$\mathrm{CO}_{2}$ to the inspired gas in a stepwise manner to increase eeCO $\mathrm{CO}_{2}$ up to $10 \%$ (for further details, see Guyenet et al., 2005). Phenylephrine (boluses of $10 \mu \mathrm{g} / \mathrm{kg}$, i.v.) was administered to raise BP. Briefly, RTN neurons were located 100-300 $\mu \mathrm{m}$ below the facial motor nucleus, they were activated by hypercapnia (up to $8-12 \mathrm{~Hz}$ at $10 \% \mathrm{eeCO}_{2}$ ), they were silenced by lowering ee $\mathrm{CO}_{2}<4 \%$, and they were unresponsive to BP elevation. RTN cells discharged tonically or exhibited a mild respiratory modulation at high $\mathrm{FiCO}_{2}$ (fraction of inspired $\mathrm{CO}_{2}$ ). To test their response to Arch activation, green light was applied continuously using the laser in 5-20 s episodes. All analog data were acquired on a computer via a micro 1401 digitizer (Cambridge Electronics), and were processed off-line using Spike software (Cambridge Electronics) (for details, see Guyenet et al., 2005). The spontaneous activity of all recorded units was determined at rest, during the photostimulation period, and in recovery.

Physiological experiments in freely behaving rats. Rats were tested in a plethysmography chamber (EMKA Technologies) custom-modified to allow tethered EEG/EMG recordings and optical stimulation. Rats were repeatedly habituated to these surroundings, which were visually isolated and with low ambient noise before the actual experiments were run. On the day of the experiment, rats were lightly anesthetized with isoflurane (induction with $5 \%$, maintenance with $2 \%$ in $100 \%$ oxygen for $<1 \mathrm{~min}$ ) to permit cleaning of hardware and connection to the ferrule and EEG/ EMG recording assembly. A $200-\mu \mathrm{m}$-thick multimode optical fiber terminated with a ferrule was mated to the implanted ferrule with a zirconia sleeve. Optical matching gel (Fiber Instrument Sales) was applied at the ferrule junction to reduce light loss. A minimum of $1 \mathrm{~h}$ was allowed for recovery from anesthesia and the emergence of stable sleep/wake patterns. Recordings were made between 10:00 A.M. to 6:00 P.M., over multiple days, with a minimum of $3 \mathrm{~d}$ rest between tests. The ventilatory response to RTN inhibition was assessed using barometric, unrestrained whole-body plethysmography (EMKA Technologies). The plethysmography chamber was continuously flushed with 1.5 $\mathrm{L} / \mathrm{min}$ of $21 \% \mathrm{O}_{2}$ balanced with $\mathrm{N}_{2}$ regulated by computer-driven mass flow controllers for $\mathrm{O}_{2}, \mathrm{~N}_{2}$, and $\mathrm{CO}_{2}$ (Alicat). Temperature and humidity within the plethysmography chamber were kept stable within experiments $\left( \pm 0.5^{\circ} \mathrm{C}, \pm 5 \%\right.$ relative humidity) and between experiments $\left(23^{\circ} \mathrm{C}-25^{\circ} \mathrm{C}\right.$ ambient room temperature, $40 \%-60 \%$ relative humidity).

Photoinhibition of Arch-expressing RTN neurons was achieved with a green laser (532 nm, Shanghai Laser and Optics Century). Photoexcitation of ChR2-expressing RTN neurons was performed using a blue laser ( $473 \mathrm{~nm}$, CrystaLaser). The lasers were controlled by TTL pulses from a Grass model S88 stimulator (AstroMed). Green light was applied bilaterally using a splitter through $200-\mu \mathrm{m}$-thick multimode optical fiber (Thorlabs) in $10 \mathrm{~s}$ episodes of continuous illumination with $\sim 5 \mathrm{~mW}$ of light output at the tip of the implanted fibers. Blue light was pulsed (2-5 $\mathrm{ms}$ pulse width) for $20 \mathrm{~s}$ periods at $20 \mathrm{~Hz}$ with $\sim 9 \mathrm{~mW}$ of light output at the tip. The transmission efficiency of each implantable optical fiber was tested before implantation with a light meter (Thorlabs).

$\leftarrow$

(Figure legend continued.) Example of a transduced CA neuron containing EYFP and TH immunoreactivity plus a Phox2b-ir nucleus. $A_{5}$, GFAP-ir cells (astrocytes, glia) are not ArchT-EYFP-ir. Arrows point to ArchT-EYFP-expressing neurons that are Phox2b-ir. Arrowhead indicates a nontransduced cell with a Phox2b-ir nucleus. $\boldsymbol{A}_{6}$, Higher-power photograph of an ArchTtransduced neuron. The GFAP-ir cells and processes are in very close proximity and do not contain EYFP. Scale bars: $\boldsymbol{A}_{1}, \boldsymbol{A}_{5}, 100 \mu \mathrm{m} ; \boldsymbol{A}_{3}, 200 \mu \mathrm{m} ; \boldsymbol{A}_{2}, \boldsymbol{A}_{4^{\prime}} \boldsymbol{A}_{6}, 20 \mu \mathrm{m}$. FN, Facial motor nucleus; vms, ventral medullary surface. $\boldsymbol{B}$, Rostrocaudal distribution of transduced RTN and CA neurons following bilateral injections of PRSx8-ArchT-EYFP lentiviral vector under the caudal end of the facial motor nucleus (30- $\mu \mathrm{m}$-thick sections, $180 \mu \mathrm{m}$ apart). $8 \mathrm{n}$, Eighth nerve root; $\mathrm{Cb}$, cerebellum; $\mathrm{DC}$, dorsal cochlear nucleus; $\mathrm{FN}$, facial motor nucleus; $\mathrm{g} 7$, genu of the seventh nerve; py, pyramidal tract; $5 \mathrm{~s} 5$, spinal trigeminal tract; vsc, ventral spinocerebellar tract. The FN extends from -12.0 to $-10 \mathrm{~mm}$ caudal to bregma. C, Location of the bilateral fiber optic tips identified in 10 rats. These sites are plotted on two transverse brain sections closest to their location; unique colors represent unique subjects. The exact transverse plane in which the fiber optic tips were found is also represented in $\boldsymbol{B}$ (triangles, same color code as in $\boldsymbol{C}$. Stereotaxic coordinates (transverse planes posterior to bregma) correspond to the atlas of Paxinos and Watson (2005).
Data acquisition and analysis. Physiological signals were acquired and processed using Spike version 7.03 software (Cambridge Electronics). EEG and EMG were amplified and bandpass filtered (EEG: $0.1-100 \mathrm{~Hz}$, $\times 1000$. EMG: $100-3000 \mathrm{~Hz}, \times 1000)$ and acquired at a sampling frequency of $1 \mathrm{kHz}$. The signal generated by the differential pressure transducer connected to the plethysmography chamber was amplified, bandpass filtered $(\times 200,0.1-20 \mathrm{~Hz})$ and acquired at a sampling frequency of $1 \mathrm{kHz}$. The signal from the radio telemetry probe (BP) was acquired at a sampling frequency of $0.2 \mathrm{kHz}$. Mean arterial pressure and heart rate were extracted from pulsatile $\mathrm{BP}$ recordings from the descending aorta based on values calibrated before implantation of the telemetry probe. Periods of wake or natural sleep were classified on the basis of EEG, EMG activity, and the patterns of cardiovascular and breathing activity. During non-rapid eye movement sleep (non-REM), EEG spectra were dominated by $\delta$ activity $(0.5-4 \mathrm{~Hz})$, with little or no EMG activity, and a stable breathing pattern, BP, and heart rate. Quiet wake was characterized by a reduction in total EEG power with EMG tone and an elevated resting heart rate.

A minimum of 6 photoactivation trials were conducted in each rat in each state (non-REM sleep and quiet wake), at each level of $\mathrm{FiO}_{2}(65 \%$, $21 \%, 15 \%$, or $12 \%$ with or without the addition of $3 \% \mathrm{FiCO}_{2}$ ) or treatment with acetazolamide ( $200 \mathrm{mg} / \mathrm{kg}$ in $100 \%$ DMSO, $0.1 \mathrm{ml}$ i.p., SigmaAldrich) or DMSO. Average breathing values were extracted from all trials not contaminated by body movements, as indicated by EMG activity. Respiratory and cardiovascular parameters (BP, heart rate) were averaged during the $10 \mathrm{~s}$ photostimulus. Baseline values were measured during the $20 \mathrm{~s}$ preceding light delivery. Respiratory frequency $\left(\mathrm{f}_{\mathrm{R}}\right.$, breaths $/ \mathrm{min})$ and tidal volume $\left(\mathrm{V}_{\mathrm{T}}\right.$, area under the curve during the inspiratory period calibrated to waveforms generated by injecting $5 \mathrm{ml}$ of dry air from a syringe during the experiment, expressed in milliliters per 100 g body weight) were calculated using Spike software version 7.3 (Cambridge Electronics). These values were used to calculate minute ventilation $\left(V_{E}=f_{R} \times V_{T}\right.$, expressed as $\mathrm{ml} / 100$ g body weight $\left./ \mathrm{min}\right)$.

Arterial blood values $\left(\mathrm{pH}, \mathrm{PCO}_{2}\right.$, bicarbonate, $\mathrm{PO}_{2}$ ) were measured at each level of $\mathrm{FiO}_{2}\left(65 \%, 21 \%, 15 \%\right.$, or $12 \%$, no $\mathrm{CO}_{2}$ added), at $12 \% \mathrm{FiO}_{2}$ with $3 \% \mathrm{FiCO}_{2}$ supplementation (isocapnic hypoxia) and with acetazolamide treatment at $65 \%, 21 \%, 15 \%$, and $12 \% \mathrm{FiO}_{2}$. Arterial blood samples were analyzed immediately with an iStat handheld monitor configured with a CG8 + cartridge (Abbott Laboratories).

All datasets were tested for normality; then differences within and between groups were determined using either paired Student's $t$ test, one-way repeated measures ANOVA, or two-way repeated-measures ANOVA with Sidak or Bonferroni multiple comparisons using PRISM software (version 6, GraphPad Software). If data were not normally distributed, Friedman's nonparametric repeated-measures ANOVA was conducted with Dunn's post hoc multiple comparisons. Two-tailed Pearson's correlation was used to test for a relationship between Archinduced reductions in breathing frequency $\left(\Delta \mathrm{f}_{\mathrm{R}}\right)$, tidal volume $\left(\Delta \mathrm{V}_{\mathrm{T}}\right)$, and minute ventilation $\left(\Delta \mathrm{V}_{\mathrm{E}}\right)$ and arterial $\mathrm{pH}(\mathrm{pHa})$ or arterial $\mathrm{PCO}_{2}$ $\left(\mathrm{PaCO}_{2}\right)$. The same test was also used to test for correlations between resting $\mathrm{f}_{\mathrm{R}}, \mathrm{V}_{\mathrm{T}}$, and $\mathrm{V}_{\mathrm{E}}$ and $\mathrm{pHa}$ or $\mathrm{PaCO}_{2}$. Linear regression analysis was used to examine the relationship between $\mathrm{pHa}$ or $\mathrm{PaCO}_{2}$ and Archinduced $\Delta \mathrm{f}_{\mathrm{R}}, \Delta \mathrm{V}_{\mathrm{T}}$, and $\Delta \mathrm{V}_{\mathrm{E}}$ and to calculate the $\mathrm{pHa}$ and $\mathrm{PaCO}_{2}$ at which RTN neurons start to be active (the recruitment threshold; methodological details in Results). All values are expressed as means \pm SEM.

Histology. Animals were deeply anesthetized with sodium pentobarbital and perfused transcardially with $4 \%$ PFA, brains removed, and processed as described previously (Abbott et al., 2012). Immunohistochemistry with antibodies against tyrosine hydroxylase (sheep anti-TH, 1:2000, Millipore), EYFP (chicken anti-GFP, 1:1000, AVES Labs), or mCherry (rabbit anti-dsRed, 1:500, Clontech \#632496, Clontech Laboratories), Phox $2 \mathrm{~b}$ (rabbit anti-Phox $2 \mathrm{~b}, 1: 8000$, a gift from J.F. Brunet, Ecole Normale Superieure, Paris), and GFAP (rat anti-GFAP, 1:1000, Invitrogen) was performed as previously described (Abbott et al., 2009b). Cell mapping, counting, and photography were done using the Neurolucida system (MicroBrightfield) with a Zeiss Axioskop microscope with computer-driven stage and Zeiss MRc camera. Cell counts were taken from a 1 in 6 series of sections, and only profiles containing a nucleus were counted. 
A1 Laser
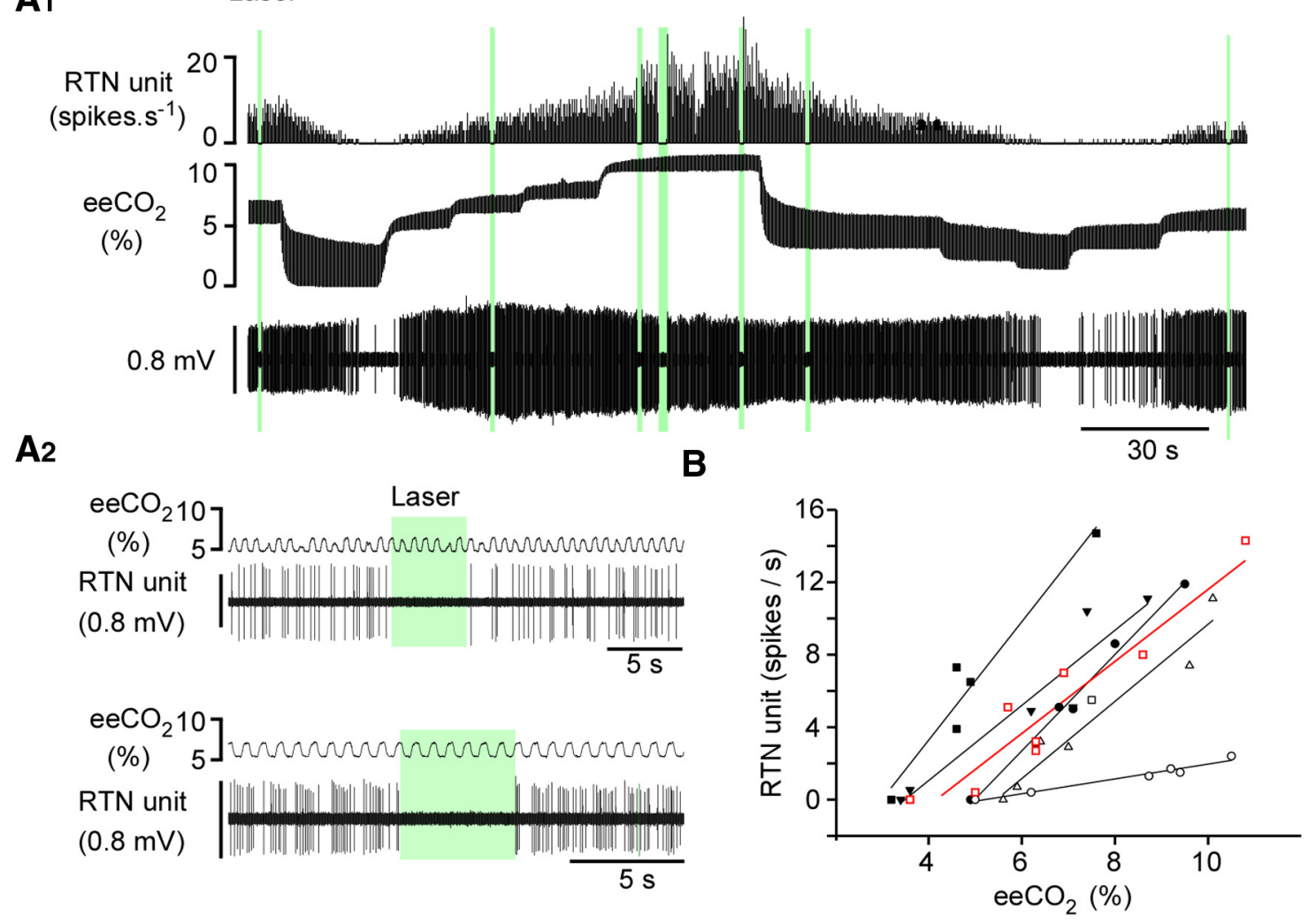

Figure 2. Arch photoactivation silences RTN neurons in anesthetized rats. $\boldsymbol{A}_{\boldsymbol{1}}$, Example of one extracellularly recorded RTN neuron. Top, Integrated rate histogram (bin size: $1 \mathrm{~s}$ ). Middle, eeC $\mathbf{O}_{2}$. Bottom, Extracellular action potentials. ee $\mathrm{CO}_{2}$ was changed by adding variable concentrations of $\mathrm{CO}_{2}$ to the breathing mixture; $532 \mathrm{~nm}$ continuous laser light was delivered in the vicinity of the neuron via a fiberoptic (green bars). The light produced immediate and complete inhibition of the neuron. $A_{2}$, Expanded scale excerpts showing that the neuron was instantly and reversibly silenced by the light under lower (top) or higher ee $\mathrm{CO}_{2}$ (bottom). $\boldsymbol{B}$, relationship between unit discharge rate and ee $\mathrm{C}_{2}$ for 6 RTN units that were silenced by green light (the cell shown in $\boldsymbol{A}_{\mathbf{1}}$ and $\boldsymbol{A}_{\mathbf{2}}$ is represented in red).

\section{Results}

\section{Histology}

The location and phenotype of Arch-transduced neurons (positive for EYFP) were examined by immunohistochemistry in 12 rats (Fig. 1). Consistent with prior studies using related PRSX8 promotercontaining LVVs (Abbott et al., 2009b), Arch-transduced neurons were limited to Phox2b-ir noncatecholaminergic neurons located just caudal to and under the entire extent of the facial motor nucleus (Fig. $1 A_{1}-A_{3}$ ) and to TH-ir neurons ( $\mathrm{C} 1$, Fig. $1 A_{4}$ ) occasionally also located in proximity to RTN but mostly present slightly caudal or medial to it (Fig. $1 A_{3}$ ). A few EYFP-labeled neurons, presumably cholinergic, were found in 3 cases within the rostral compact portion of nucleus ambiguus and were not included in the count of RTN cells. The TH-negative transduced neurons located under the facial motor nucleus were virtually all Phox $2 \mathrm{~b}$-positive and therefore classified as RTN neurons (Abbott et al., 2009b). The rostrocaudal distribution of Archtransduced RTN and catecholaminergic (CA) neurons is shown in Figure $1 B$ (12 rats). The total number of Arch-transduced RTN neurons counted in a 1 in 6 series of coronal sections was $85.8 \pm$ 11.3 neurons. The number of transduced CA neurons counted was $81.2 \pm 9$. Figure $1 C$ shows where the tips of optical fibers were located in 10 of these rats (Fig. $1 B, C$ ). Two of the 12 rats had a correctly placed optical fiber on one side only and are not represented.

The distribution of ChR2-transduced neurons was very similar albeit unilateral by design. On average, $67 \pm 11$ neurons ( 1 in 6 section counts) expressed EYFP, of which $33 \pm 8$ also expressed
$\mathrm{TH}(47 \%)$. The optical fiber tips were located $0.5-1 \mathrm{~mm}$ dorsal to the ventral medullary surface at levels 9.7-11.5 caudal to bregma similar to the placement of optical fibers in the Arch cases shown in Figure 1.

Astrocytes regulate RTN neurons by releasing ATP (Gourine et al., 2010). Although astrocytes are not known to express Phox $2 \mathrm{~b}$, we tested whether Arch might have been expressed by these cells. In sections from four PRSX8-Arch-EYFP LVVinjected rats, no overlap between GFAP immunoreactivity and EYFP could be detected in the RTN, although glia are located in close proximity to the transduced neurons as reported previously (Fig. $1 A_{5}, A_{6}$ ) (Lazarenko et al., 2009).

\section{Photoactivation of the proton pump silences RTN in anesthetized rats}

Arch is a light-activated pump that translocates protons from the cytoplasm to the extracellular space, thereby hyperpolarizing and silencing neurons (Chow et al., 2010). Given that RTN neurons are directly activated by acidification in slices (Mulkey et al., 2004; Wang et al., 2013a, b), we wanted to ascertain that Arch activation can indeed silence RTN neurons (i.e., that the protons translocated by the pump do not stimulate these cells in vivo). We identified 9 RTN neurons in 4 rats in which RTN neurons were transduced with Arch. Six of those were silenced by applying green light for $2-10 \mathrm{~s}$ (Fig. $2 A_{1}$ ). The rest were unaffected. Inhibition was immediate, instantly reversible, and complete, including when the neurons were maximally activated by $10 \% \mathrm{FiCO}_{2}$ (Fig. $2 A_{1}, A_{2}$ ). The inhibited neurons had the characteristic prop- 
erties of previously identified Phox 2b-positive RTN chemoreceptors (i.e., they were silent at eeCO $\mathrm{CO}_{2}<3.5 \%-4.5 \% \mathrm{eeCO}_{2}$, robustly activated by hypercapnia in a concentration-dependent manner and respiratory-modulated at high levels of eeCO $\mathrm{C}_{2}$ only) (Fig. $2 A_{1}, B$ ). Thus, despite their intrinsic sensitivity to acid, RTN neurons are inhibited by Arch similar to other previously tested neurons (Chow et al., 2010). Given the uncertainty regarding whether intracellular or extracellular acidification is responsible for the acid-induced depolarization of RTN neurons, several explanations are plausible. First, the Arch-dependent outward current could deliver too few protons to acidify the extracellular space. Second and more likely, the pump generates an outward current that is far greater than the maximal inward current caused by extracellular acidification of RTN neurons (typically 20-30 pA in slices) (Mulkey et al., 2004; Wang et al., 2013a, 2013b). Third, if the potassium conductance responsible for the acid sensitivity of RTN neurons is closed by intracellular rather than extracellular acidification, the intracellular alkalization caused by Arch could actually contribute to inhibiting RTN neurons.

\section{Arch-triggered hypoventilation is attenuated by hypoxia}

These physiological experiments were designed to test several consequences of the theory that RTN neurons are CRCs and/or function as a central respiratory chemoreflex integrator, namely: (1) RTN neuron inhibition should produce hypoventilation at rest; (2) activity of RTN neurons should be reduced by hypoxia because of the associated alkalosis; (3) during hypoxia, RTN neurons should be reactivated by restoring blood acidity to control (normoxic) levels; and (4) RTN neurons should be activated by hyperoxia. Collectively, these four criteria form a reasonably stringent test of whether RTN mediates the effects of brain acidification on breathing with any degree of selectivity. The first test distinguishes between neurons that drive breathing at rest and neurons that do not. The second one distinguishes between neurons that mediate the effect of CNS hypercarbia and neurons that merely contribute to respiratory rhythm and pattern generation. Contrary to the former, the latter should be activated by hypoxia because this stimulus activates the breathing rate and amplitude. The third criterion verifies the expectation that hypoxia inhibits RTN neurons via brain alkalization. The fourth criterion also distinguishes potential CRCs from neurons that contribute to respiratory rhythm and pattern generation. Indeed, because hyperoxia decreases breathing in rats (Olson et al., 1988), the activity of the latter should be reduced in a manner commensurate with the reduction in breathing intensity, whereas CRCs should be activated. Criteria 1,2, and 4 are addressed in this section; the third criterion is examined later on.

Blood gases were measured while rats were quiescent and fully habituated to their surroundings to minimize the confounding effect of stress and physical activity on ventilation. Blood gases during normoxia, hypoxia, and hyperoxia conformed to expectations for rats (Olson et al., 1988) (Table 1). Hyperoxia caused a slight respiratory acidosis (not significant), and hypoxia caused frank respiratory alkalosis at $12 \% \mathrm{FiO}_{2}(N=6$; one-way repeated-measures ANOVA across four levels of $\mathrm{FiO}_{2}$ for $\mathrm{pH}$, $\mathrm{PaCO}_{2}, \mathrm{PaO}_{2}$, and $\mathrm{HCO}_{3}$; effect on $\mathrm{pH}$ : Friedman statistic = $18.00, p<0.001$; Dunn's multiple comparisons for $\mathrm{pH}: 65 \%$ vs $21 \% \mathrm{FiO}_{2}, p>0.9 ; 21 \%$ vs $\left.12 \% \mathrm{FiO}_{2}, p=0.04\right)$. Arch photoactivation was administered exclusively during periods of eupneic breathing (i.e., when rats were quietly awake or in non-REM sleep and breathing was regular). Periods of REM sleep or epi-
Table 1. Blood gases in conscious rats

\begin{tabular}{|c|c|c|c|c|c|}
\hline Variable & $n$ & $\mathrm{pH}$ & $\mathrm{PaCO}_{2}$ & $\mathrm{PaO}_{2}$ & $\mathrm{HCO}_{3}$ \\
\hline $65 \% \mathrm{FiO}_{2}$ & 6 & $7.40 \pm 0.01$ & $49.2 \pm 2.3$ & $271 \pm 8.2$ & $30.4 \pm 1.2$ \\
\hline $21 \% \mathrm{FiO}_{2}$ & 6 & $7.44 \pm 0.01$ & $41.8 \pm 1.9$ & $78.3 \pm 3$ & $29.0 \pm 1.7$ \\
\hline $15 \% \mathrm{FiO}_{2}$ & 6 & $7.51 \pm 0.01 \dagger$ & $32.6 \pm 0.9$ & $51.5 \pm 2.6$ & $26.1 \pm 0.8 \dagger$ \\
\hline $12 \% \mathrm{FiO}_{2}$ & 6 & $7.59 \pm 0.01^{*, t+\dagger}$ & $25.0 \pm 0.6^{*,+t \dagger}$ & $43.0 \pm 2.4$ & $23.9 \pm 0.9^{*, t+\dagger}$ \\
\hline $\begin{array}{r}12 \% \mathrm{FiO}_{2}+ \\
3 \% \mathrm{FiCO}_{2}\end{array}$ & 5 & $7.48 \pm 0.02$ & $34.5 \pm 0.9$ & $56.6 \pm 3.3$ & $25.7 \pm 0.3$ \\
\hline $\mathrm{ACTZ}+65 \% \mathrm{FiO}_{2}$ & 4 & $7.36 \pm 0.01$ & $40.6 \pm 2.0$ & $287 \pm 6.8$ & $22.5 \pm 0.5$ \\
\hline $\mathrm{ACTZ}+21 \% \mathrm{FiO}_{2}$ & 4 & $7.38 \pm 0.01$ & $40.3 \pm 1.4$ & $100 \pm 2.2$ & $24.0 \pm 0.6$ \\
\hline $\mathrm{ACTZ}+15 \% \mathrm{FiO}_{2}$ & 4 & $7.40 \pm 0.01$ & $32.7 \pm 0.6$ & $63.8 \pm 1.5$ & $20.2 \pm 0.7$ \\
\hline $\mathrm{ACTZ}+12 \% \mathrm{FiO}_{2}$ & 4 & $7.43 \pm 0.01^{\dagger}$ & $28.0 \pm 0.8^{\dagger}$ & $51.5 \pm 2.0$ & $18.5 \pm 0.8^{*}$ \\
\hline
\end{tabular}

Blood gases were measured in quietly resting rats habituated to the plethysmography chamber during exposure to various breathing mixtures. ACTZ, Acetazolamide.

*The $21 \%$ versus 15 or $12 \% \mathrm{FiO}_{2}$ (one symbol: $p<0.05$; three symbols: $p<0.005$ ).

${ }^{\dagger}$ The $65 \%$ versus $15 \%$ or $12 \% \mathrm{FiO}_{2}$ (one symbol: $p<0.05$; three symbols: $p<0.005$ ).

sodes during which rats were actively behaving (grooming, sniffing, ambulating) were deliberately excluded from testing.

Hyperoxia reduced resting ventilation slightly, whereas hypoxia produced the expected oxygen concentration-dependent stimulation of breathing rate (Fig. $3 A, B$ ). Arch activation consistently reduced breathing rate and amplitude during normoxia (Fig. $3 A, B$ ). Arch-induced hypoventilation was increased by hyperoxia $\left(65 \% \mathrm{FiO}_{2}\right)$, attenuated by hypoxia $\left(15 \% \mathrm{FiO}_{2}\right)$, and dramatically reduced at $12 \% \mathrm{FiO}_{2}$ (Fig. $\left.3 A-C\right)(N=9$; two-way repeated-measures ANOVA; effect of $\mathrm{FiO}_{2}$ on $\mathrm{f}_{\mathrm{R}}: F_{(3,24)}=30.71$, $p<0.0001$; effect of Arch on $\mathrm{f}_{\mathrm{R}}: F_{(1,8)}=36.91, p=0.0003$; interaction effect on $\mathrm{f}_{\mathrm{R}}: F_{(3,24)}=32.04, p<0.0001$; Sidak's multiple comparisons of $\mathrm{f}_{\mathrm{R}}$ values: $65 \% \mathrm{FiO}_{2}$ vs $65 \% \mathrm{FiO}_{2}+$ Arch, $p<0.0001 ; 21 \% \mathrm{FiO}_{2}$ vs $21 \% \mathrm{FiO}_{2}+$ Arch, $p<0.0001 ; 15 \% \mathrm{FiO}_{2}$ vs $15 \% \mathrm{FiO}_{2}+$ Arch, $p=0.05 ; 12 \% \mathrm{FiO}_{2}$ vs $12 \% \mathrm{FiO}_{2}+$ Arch, $p>0$. 9; effect of $\mathrm{FiO}_{2}$ on $\mathrm{V}_{\mathrm{T}}: F_{(3,24)}=0.96, p=0.43$; effect of Arch on $\mathrm{V}_{\mathrm{T}}: F_{(1,8)}=72.17, p<0.0001$; interaction effect on $\mathrm{V}_{\mathrm{T}}$ : $F_{(3,24)}=19.67, p<0.0001$; Sidak's multiple comparisons of $\mathrm{V}_{\mathrm{T}}$ values: $65 \% \mathrm{FiO}_{2}$ vs $65 \% \mathrm{FiO}_{2}+\mathrm{Arch}, p<0.0001 ; 21 \% \mathrm{FiO}_{2}$ vs $21 \% \mathrm{FiO}_{2}+$ Arch, $p<0.0001 ; 15 \% \mathrm{FiO}_{2}$ vs $15 \% \mathrm{FiO}_{2}+$ Arch, $p<0.0001 ; 12 \% \mathrm{FiO}_{2}$ vs $12 \% \mathrm{FiO}_{2}+$ Arch, $p<0.0001$; effect of $\mathrm{FiO}_{2}$ on $\mathrm{V}_{\mathrm{E}}: F_{(3,24)}=23.13, p<0.0001$; effect of Arch on $\mathrm{V}_{\mathrm{E}}: F_{(1,8)}$ $=77.0, p<0.0001$; interaction effect on $\mathrm{V}_{\mathrm{E}}: F_{(3,24)}=35.94, p<$ 0.0001; Sidak's multiple comparisons between $\mathrm{V}_{\mathrm{E}}$ values: $65 \%$ $\mathrm{FiO}_{2}$ vs $65 \% \mathrm{FiO}_{2}+$ Arch, $p<0.0001 ; 21 \% \mathrm{FiO}_{2}$ vs $21 \% \mathrm{FiO}_{2}+$ Arch, $p<0.0001 ; 15 \% \mathrm{FiO}_{2}$ vs $15 \% \mathrm{FiO}_{2}+$ Arch, $p<0.0001$; $12 \% \mathrm{FiO}_{2}$ vs $12 \% \mathrm{FiO}_{2}+$ Arch, $p<0.0001$ ).

Arch-induced hypoventilation was maximal during the early part of the photostimulus and tended to return toward the prestimulation level thereafter. The tendency for breathing to increase during the latter part of the photostimulus period can be better appreciated by examining event-triggered averaged responses (Fig. 4). These graphs show that the hypoventilation was better sustained throughout the light stimulus during hyperoxia than during hypoxia. This in turn suggests that, during normoxia and especially so during hypoxia, the hypoventilation elicited by the photostimulus was rapidly attenuated by an increase in $\mathrm{CB}$ activity rather than by an increase in CRC activity. This interpretation is based on the peripheral chemoreflex having a much shorter time constant than the central chemoreflex (Smith et al., 2006). The relaxation of the hypoventilation during the latter part of the photostimulus indicates that we slightly underestimated the instantaneous contribution of RTN neurons to resting ventilation by averaging breathing frequency and tidal volume throughout the $10 \mathrm{~s}$ stimulus period.

Arterial pressure (BP) was recorded by telemetry in 4 rats. Resting BP was unaffected by the level of inhaled oxygen except 

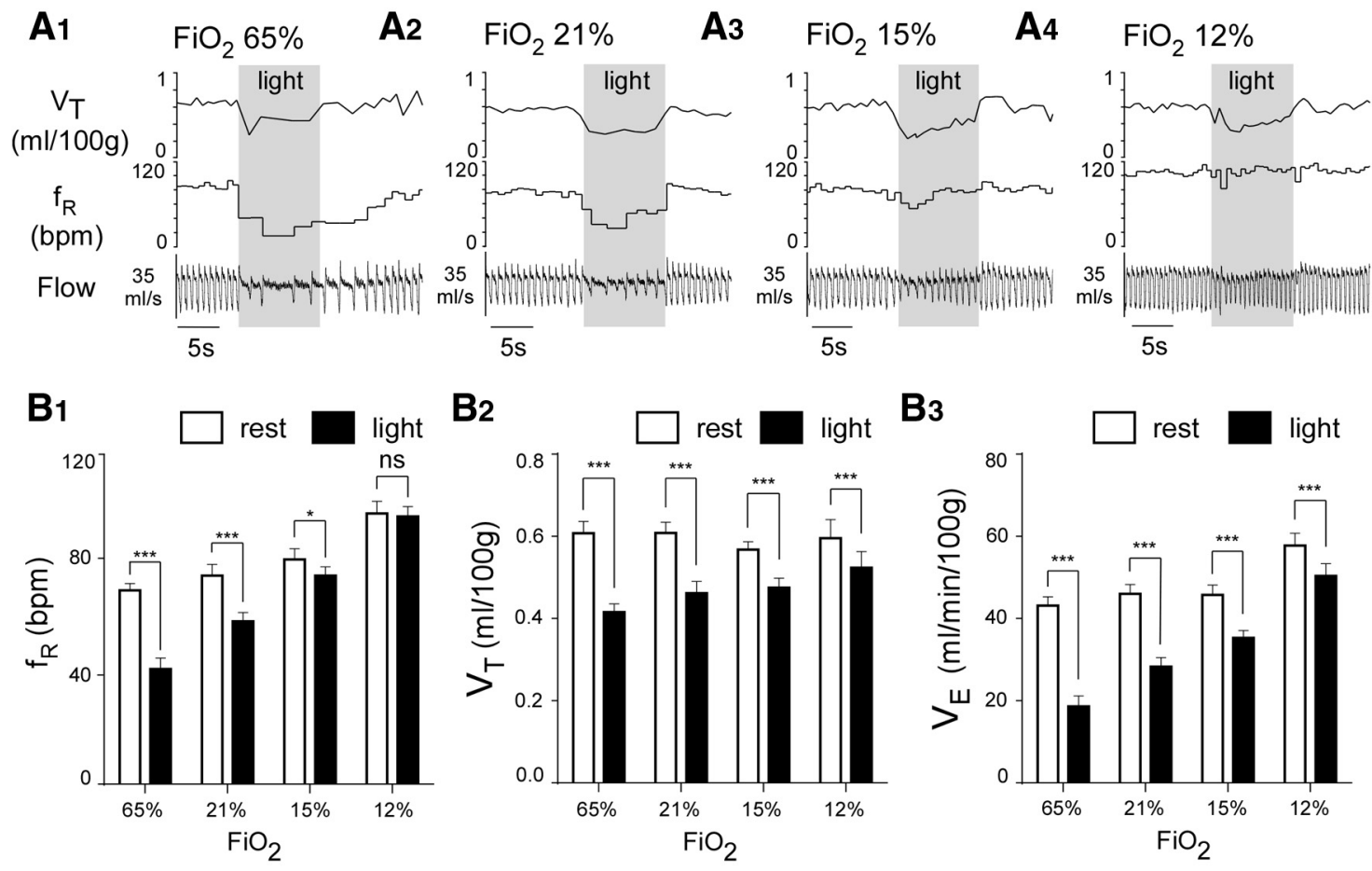

B2

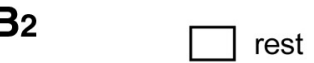
rest light

B3
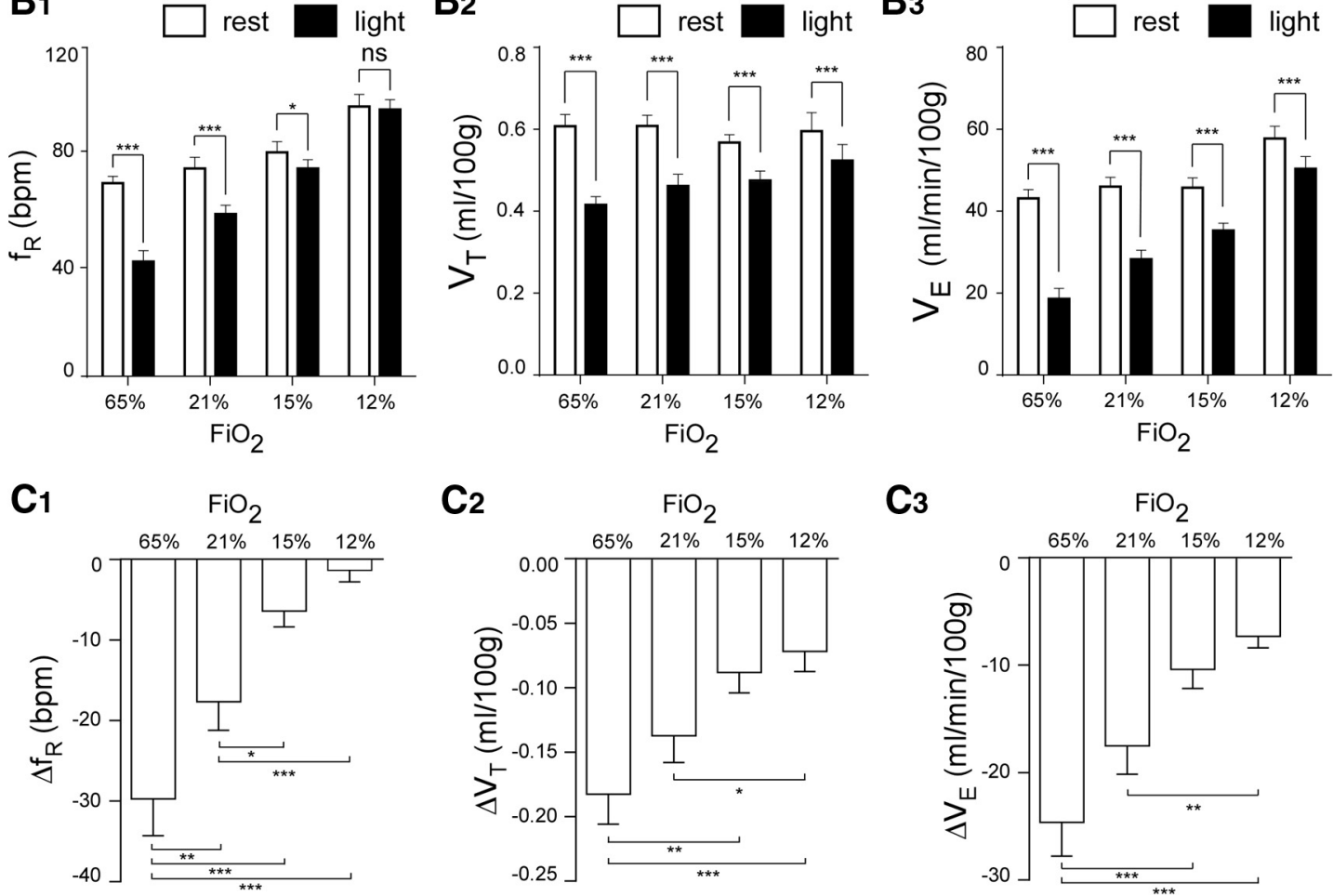

$\mathrm{C}_{2}$
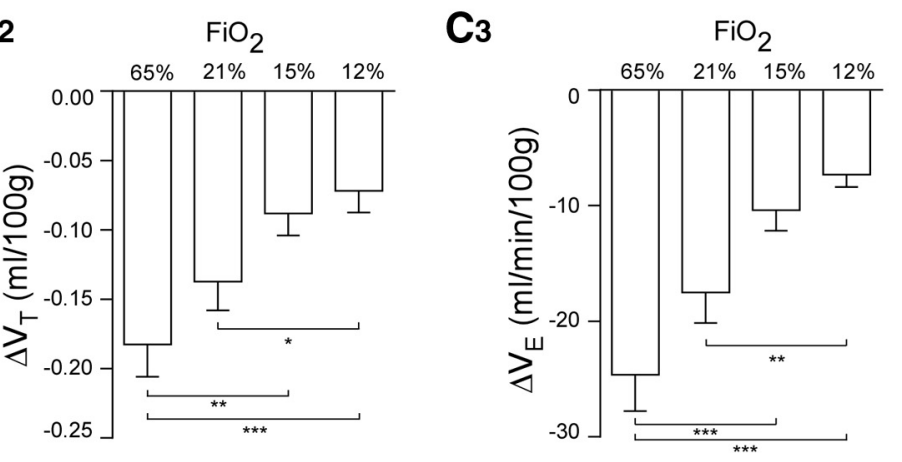

Figure 3. Arch photoactivation reduces breathing rate and amplitude to different extents in conscious rats exposed to normoxia, hyperoxia, or hypoxia. $A$, Hypoventilation caused by bilateral Arch photoactivation (10 s) in a conscious Sprague Dawley rat under hyperoxia $\left(65 \% \mathrm{FiO}_{2}, \boldsymbol{A}_{1}\right)$, normoxia $\left(21 \% \mathrm{FiO}_{2}, \boldsymbol{A}_{2}\right)$, mild hypoxia $\left(15 \% \mathrm{FiO}_{2}, \boldsymbol{A}_{3}\right)$, and moderate hypoxia $\left(12 \% \mathrm{FiO}{ }_{2}, \boldsymbol{A}_{4}\right), \boldsymbol{B}$, Ventilation parameters at rest and during Arch photostimulation in rats exposed to four levels (percentages) of $\boldsymbol{O}_{2}$ in the breathing mixture (FiO $\left.{ }_{2}\right)$ : group data ( 9 rats). $\boldsymbol{B}_{1}, \mathrm{f}_{\mathrm{R}}$ at rest and during Arch photostimulation. $\boldsymbol{B}_{2}, V_{T}$ at rest and during Arch photostimulation. $\boldsymbol{B}_{3}, V_{\mathrm{E}}$ at rest and during Arch photostimulation. $\boldsymbol{C}$, Change in ventilation parameters elicited by Arch photostimulation across four levels of $\mathrm{FiO}_{2}$ : group data (same 9 rats as in $\boldsymbol{B}$ ). $\boldsymbol{C}_{1}$, Effect of $\mathrm{FiO}_{2}$ on $\Delta \mathrm{f}_{\mathrm{R}}$. $\boldsymbol{C}_{2}$, Effect of $\mathrm{FiO}_{2}$ on $\Delta \mathrm{V}_{\mathrm{T}}$. $\boldsymbol{C}_{3}$, Effect of $\mathrm{FiO}_{2}$ on $\Delta \mathrm{V}_{\mathrm{E}} .{ }^{*} p<0.05$. ${ }^{* *} p<0.01$. ${ }^{* * *} p<0.001$.

for a slight reduction at $12 \% \mathrm{FiO}_{2}$ (Fig. 5). Arch photoactivation $(10 \mathrm{~s})$ produced a small hypotension under all levels of $\mathrm{FiO}_{2}$ (Fig. 5) $\left(\mathrm{N}=4\right.$; two-way repeated-measures ANOVA; effect of $\mathrm{FiO}_{2}$ on BP: $F_{(3,9)}=4.440, p=0.03$; effect of Arch on BP: $F_{(1,3)}=19.14$, $p=0.02$; interaction effect on BP: $F_{(3,9)}=14.73, p=0.0008$; Sidak's multiple comparisons for effect of $\mathrm{FiO}_{2}$ on resting BP: comparisons between every level of $\mathrm{FiO}_{2}$, except those for $12 \%$ $\mathrm{FiO}_{2}, p>0.3$; for all $\mathrm{FiO}_{2}$ levels vs $12 \%, p<0.0001$; Sidak's multiple comparisons for BP before and after Arch photoactivation at $65 \% \mathrm{FiO}_{2}, p=0.05 ; 21 \% \mathrm{FiO}_{2}, p=0.002 ; 15 \% \mathrm{FiO}_{2}, p=$ $\left.0.0002 ; 12 \% \mathrm{FiO}_{2}, p<0.0001\right)$. The rostral $\mathrm{C} 1$ cells innervate and drive vasomotor sympathetic preganglionic neurons. Their activity is increased by hypoxia and helps maintain BP during hypoxia (Sun and Reis, 1994; Hirooka et al., 1997; Madden and Sved, 2003). Hypoxia-dependent hypotension was therefore an expected consequence of inhibiting a subset of $\mathrm{C} 1$ neurons transduced with Arch. The hypotension was very small, however, suggesting that few $\mathrm{C} 1$ cells were inhibited or that the baroreflex strongly buffered the response by activating the nontransduced C1 neurons.

The hypoventilation elicited by activating Arch was correlated with the number of transduced RTN neurons $(N=10$; correlation with $\mathrm{f}_{\mathrm{R}}$ : Pearson $r=0.64$, one-tailed $p=0.03$; correlation with $\mathrm{V}_{\mathrm{T}}$ : Pearson $r=0.66, p=0.02$; correlation with $\mathrm{V}_{\mathrm{E}}$ : Pearson $r=0.59, p=0.04)$ and exhibited only a weak correlation with the number of transduced CA cells (correlation with $\mathrm{f}_{\mathrm{R}}$ : Pearson $r=$ 0.52 , one-tailed $p=0.06$; correlation with $\mathrm{V}_{\mathrm{T}}$ : Pearson $r=0.55$, $p=0.05$; correlation with $\mathrm{V}_{\mathrm{E}}$ : Pearson $r=0.60, p=0.03$ ) (Fig. $6 \mathrm{~A}, \mathrm{~B})$. A total of $10 \mathrm{~mW}$ of blue light delivered by a $200 \mu \mathrm{m}$ optical fiber delivers $\geq 1 \mathrm{~mW}$, the power necessary to activate ChR2, only through $0.5 \mathrm{~mm}^{3}$ of tissue (a sphere of $\sim 500 \mu \mathrm{m}$ radius) (Aravanis et al., 2007). When we considered only the transduced neurons located within $500 \mu \mathrm{m}$ of the coronal plane of optical fibers (10 rats; Fig. 6C), the correlation between hypoventilation and transduced RTN neurons became much tighter (correlation with $\mathrm{f}_{\mathrm{R}}$ : Pearson $r=0.74, p=0.008$; correla- 


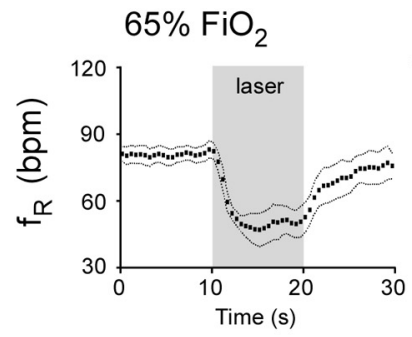

$65 \% \mathrm{FiO}_{2}$

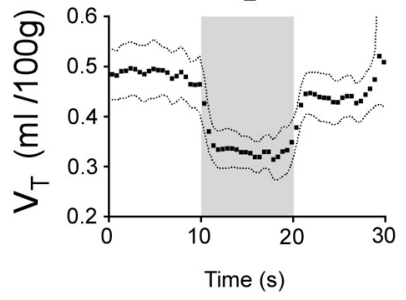

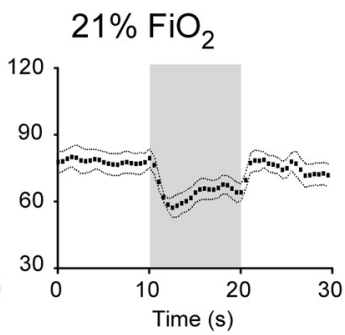

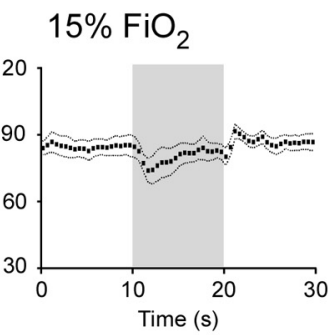

$15 \% \mathrm{FiO}_{2}$
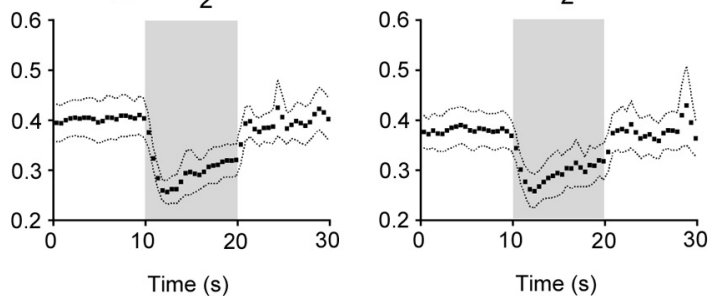
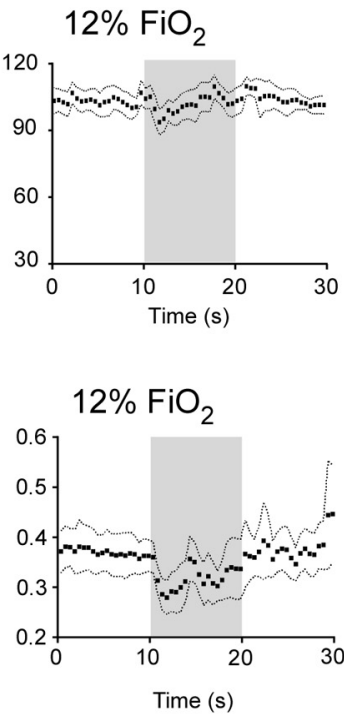

Figure 4. Kinetics of the hypoventilatory response at four different levels of Fi0 ${ }_{2}$. Event-triggered averaged ventilatory responses to bilateral activation of Arch. Five or six responses were collected at each $\mathrm{FiO}_{2}$ in every rat $(\mathrm{N}=5)$ to generate a single average response per rat. Five such responses were averaged. The mean and $5 \%$ confidence intervals are shown.

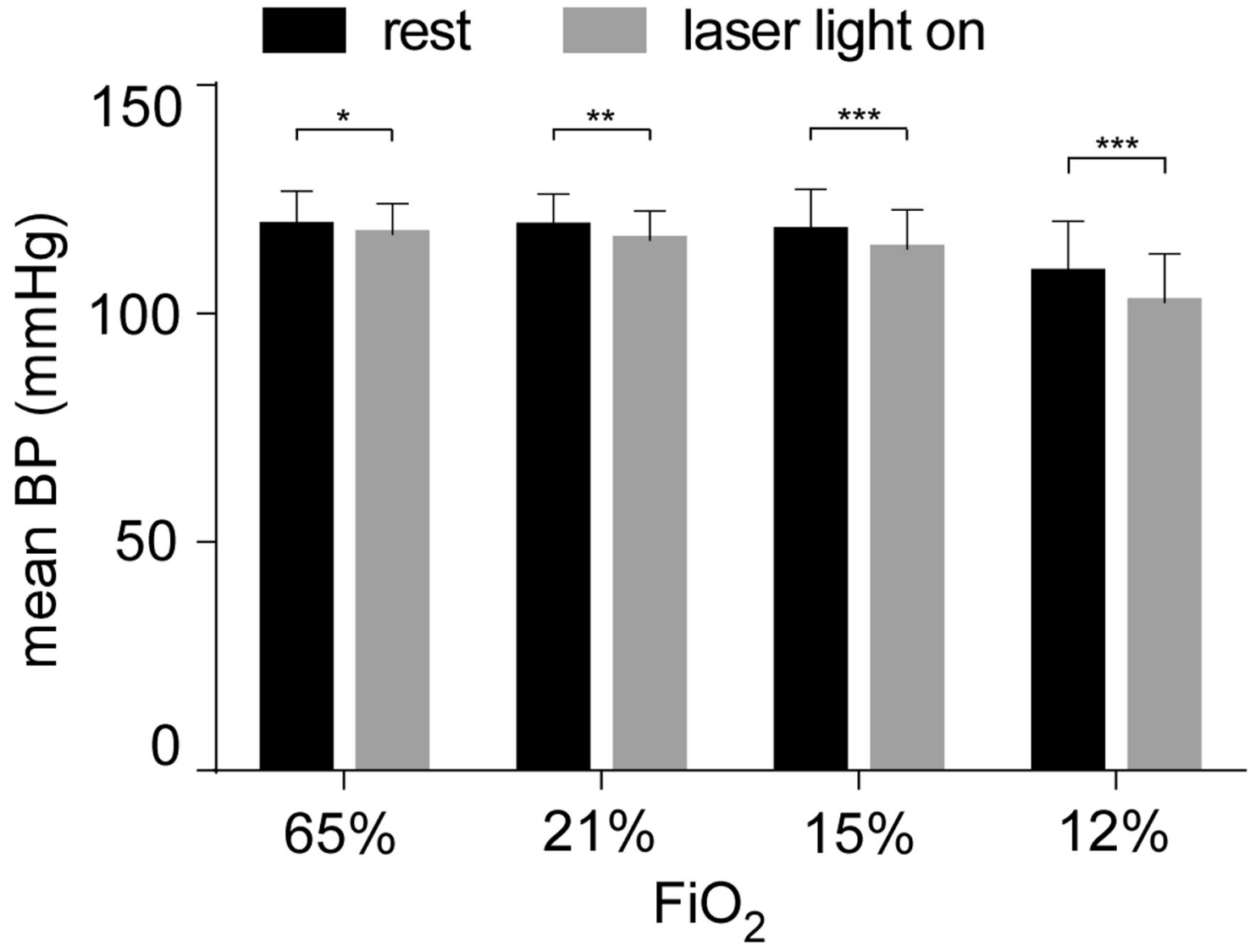

Figure 5. Effect of hypoxia on resting BP and on the BP response to Arch stimulation. BP measurements at rest (black bars) and during Arch stimulation (gray bars) in 4 Sprague Dawley rats under hyperoxia $\left(65 \% \mathrm{FiO}_{2}\right)$, normoxia $\left(21 \% \mathrm{FiO}_{2}\right)$, mild hypoxia $\left(15 \% \mathrm{FiO}_{2}\right)$, and moderate hypoxia $\left(12 \% \mathrm{FiO}_{2}\right) .{ }^{*} p<0.05 .{ }^{* *} p<0.01 .{ }^{* * *} p<0.001$.

tion with $\mathrm{V}_{\mathrm{T}}$ : Pearson $r=0.86, p=0.0008$; correlation with $\mathrm{V}_{\mathrm{E}}$ : Pearson $r=0.86, p=0.0007$ ), whereas there was even less correlation with the number of transduced CA cells located in the same domain (correlation with $\mathrm{f}_{\mathrm{R}}$ : Pearson $r=0.48, p=0.08$; correlation with $\mathrm{V}_{\mathrm{T}}$ : Pearson $r=0.43, p=0.1$; correlation with $\mathrm{V}_{\mathrm{E}}$ : Pearson $r=0.63, p=0.03$ ) (Fig. $6 D$ ). Linear regression analysis further revealed that the relationship between the num- ber of transduced RTN neurons and the respiratory effects produced during Arch photoinhibition was more robust than that between numbers of CA neurons transduced particularly when distance from the fiber optic tip was taken into consideration (Fig. 6) (percentage decrease in $\mathrm{f}_{\mathrm{R}}$ and number of RTN neurons: $r^{2}=0.54, p=0.02$; percentage decrease in $\mathrm{V}_{\mathrm{T}}: r^{2}=0.73, p=$ 0.002 ; percentage decrease in $\mathrm{V}_{\mathrm{E}}: r^{2}=0.74, p=0.001$ ). Thus, the 
A

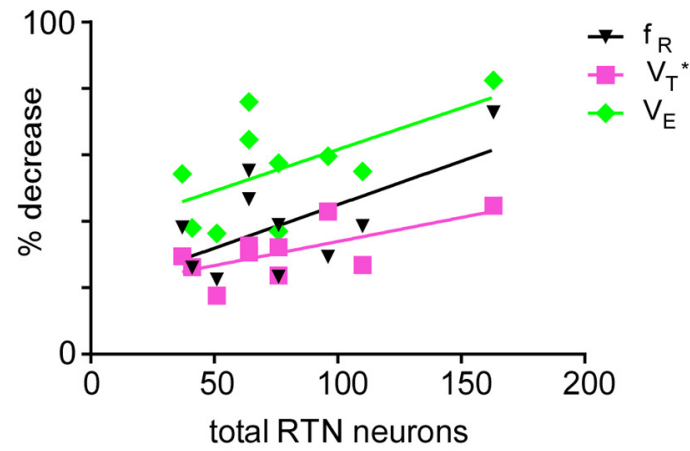

B

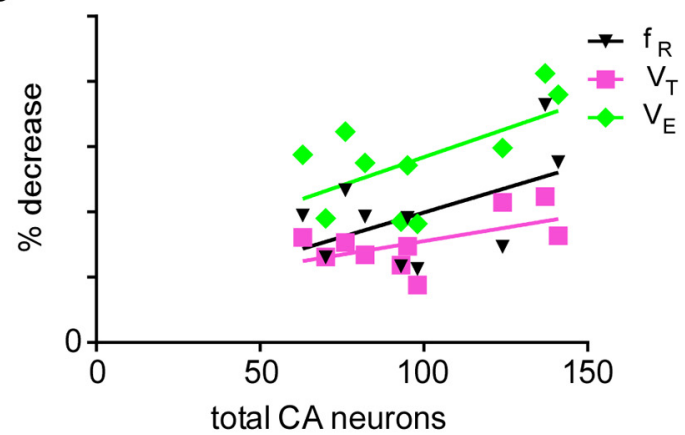

C

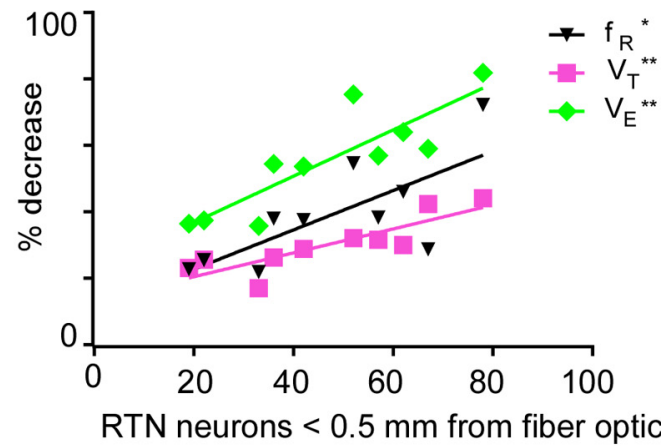

D

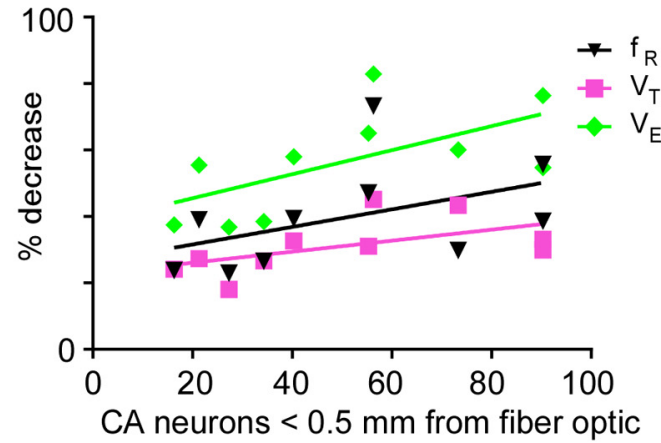

Figure 6. Relationship determined by linear regression between Arch-induced hypoventilation and the number of Arch-transduced neurons. $\boldsymbol{A}$, Relationship between number of all RTN neurons transduced (counted in a 1:6 coronal series) and percentage decrease of $f_{R^{\prime}}, V_{T}$, and $V_{E}$ elicited by Arch photostimulation for 10 Sprague Dawley rats. $\boldsymbol{B}$, Relationship between number of all catecholaminergic (CA) neurons transduced and percentage decrease of $f_{R}, V_{T}$, and $V_{E}$ (for the same 10 Sprague Dawley rats as in $\boldsymbol{A}$ ) elicited by Arch photostimulation. $\boldsymbol{C}$, Relationship between numbers of RTN neurons within $0.5 \mathrm{~mm}$ of the coronal plane containing the fiber optic tip. $D$, Relationship between numbers of CA neurons within $0.5 \mathrm{~mm}$ of the coronal plane containing the fiber optic tip. ${ }^{*} p<0.05$. ${ }^{* *} p<0.01$.

hypoventilation elicited by the light was likely caused by inhibition of Arch-transduced RTN neurons as opposed to catecholaminergic neurons. The results also suggest that the light may not have been able to reach the entire population of transduced RTN neurons. In this cohort of 10 rats, the number of Arch-transduced RTN neurons located within $500 \mu \mathrm{m}$ of the tip of optical fibers varied from a low of 120 to a high of 480 (the number of counted neurons in a 1 in 6 series of sections multiplied by 6) and the total number of transduced RTN neurons was between 240 and 980 . Because the rat has $\sim 2000$ RTN neurons, we estimate that the maximum percentage of RTN neurons that were directly photoinhibited could not have exceeded $50 \%$; yet, in hyperoxia, $\mathrm{V}_{\mathrm{E}}$ could be reduced by up to $80 \%$.

\section{Does arousal account for the loss of Arch-triggered hypoventilation during hypoxia?}

Hypoxia causes arousal (Pappenheimer, 1977; Phillipson et al., 1978), and the contribution of RTN neurons to breathing has been previously described as state-dependent (Li et al., 1999). To test whether the loss of Arch-triggered hypoventilation during hypoxia was caused by arousal, we compared the responses elicited under the following three conditions: normoxia when rats were in non-REM sleep, normoxia during wake, and $12 \% \mathrm{FiO}_{2}$ while the animals were quietly awake. The state of vigilance was determined by video recording of the animal's immobility and posture and by examining the $\delta$ power $(0.5-4 \mathrm{~Hz})$ of the EEG. The hypoventilation elicited under normoxic conditions during nonREM sleep was about the same as when rats were quietly awake (Fig. 7). The hypoventilation observed during hypoxia in quiet awake rats was still significantly smaller than when rats were qui- etly awake under normoxia (Fig. $7 B)(N=5$; one-way repeatedmeasures ANOVA; main effect of laser light on $\Delta \mathrm{f}_{\mathrm{R}}: F_{(2,12)}=$ 11.79, $p=0.002$. Bonferroni multiple comparisons: $21 \% \mathrm{FiO}_{2}$ quiet awake vs $21 \% \mathrm{FiO}_{2}$ non-REM sleep, $p>0.9 ; 21 \% \mathrm{FiO}_{2}$ quiet awake vs $12 \% \mathrm{FiO}_{2}$ quiet awake, $p=0.002 ; 21 \% \mathrm{FiO}_{2}$ non-REM sleep vs $12 \% \mathrm{FiO}_{2}$ quiet awake, $p=0.007$; effect of laser light on $\Delta \mathrm{V}_{\mathrm{T}}: F_{(2,12)}=1.556, p=0.3$; effect of light on $\Delta \mathrm{V}_{\mathrm{E}}: F_{(2,12)}=$ 9.136, $p=0.004$; Bonferroni multiple comparison: $21 \% \mathrm{FiO}_{2}$ quiet awake vs $12 \% \mathrm{FiO}_{2}$ quiet awake, $p=0.01 ; 21 \% \mathrm{FiO}_{2}$ nonREM sleep vs $12 \% \mathrm{FiO}_{2}$ quiet awake, $p=0.008 ; 21 \% \mathrm{FiO}_{2}$ quiet awake vs $21 \% \mathrm{FiO}_{2}$ non-REM sleep, $p>0.9$ ). FFT analysis of the EEG (with values normalized to non-REM sleep) showed that the $\delta$ power $(0.5-4 \mathrm{~Hz})$ was the same during quiet awake and hypoxia and that the $\delta$ power under both conditions was significantly less than during non-REM sleep (Fig. $7 C)(N=5$; one-way repeated-measures ANOVA; $F_{(2,8)}=15.08, p=0.002$; Bonferroni's multiple comparisons: $21 \% \mathrm{FiO}_{2}$ non-REM sleep vs $21 \% \mathrm{FiO}_{2}$ quiet awake, $p=0.003 ; 21 \% \mathrm{FiO}_{2}$ non-REM sleep vs $12 \% \mathrm{FiO}_{2}$ quiet awake, $p=0.006 ; 21 \% \mathrm{FiO}_{2}$ quiet awake vs $12 \% \mathrm{FiO}_{2}$ quiet awake, $\left.p>0.9\right)$.

In summary, RTN neurons drive eupneic breathing equally during non-REM sleep and quiet waking in rats. Second, arousal does not account for the reduction of Arch-triggered hypoventilation during hypocapnic hypoxia.

Does hypoxia attenuate the breathing stimulation elicited by RTN stimulation?

A possible reason why hypoxia attenuates Arch-triggered hypoventilation could be that the respiratory network is unable to respond to RTN neuronal input under this condition. To address 
A1

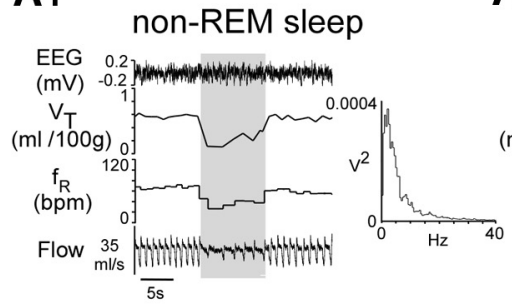

A2

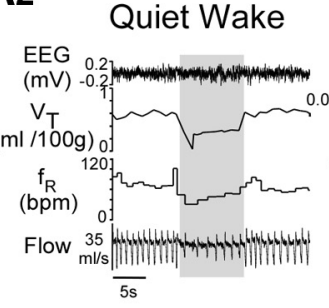

A3

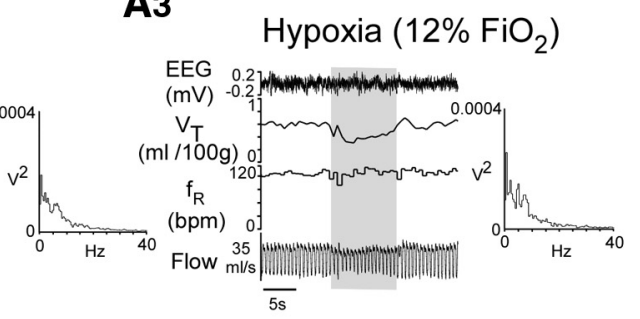

B1

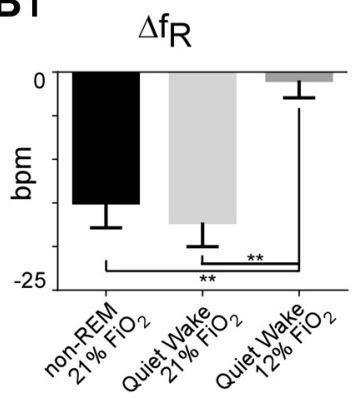

B2

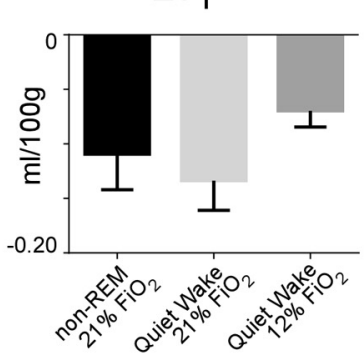

B3

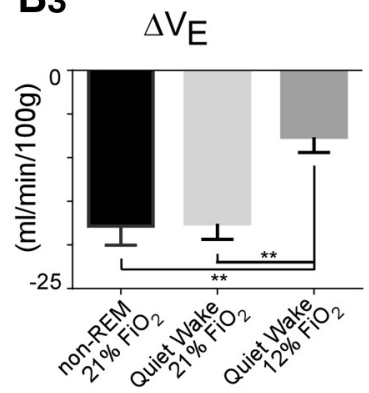

C

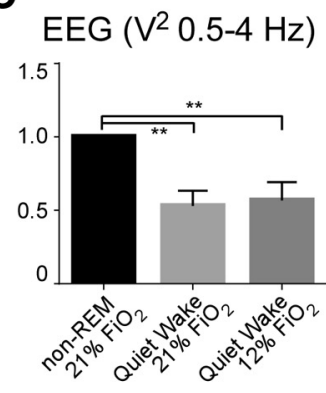

Figure 7. Arousal does not account for the reduction of Arch-triggered hypoventilation during hypoxia. $A$, Hypoventilation caused by bilateral Arch photoactivation (10 $s$, gray shaded bars) in one Sprague Dawley rat during non-REM sleep $\left(\boldsymbol{A}_{1}\right)$, quiet wake $\left(\boldsymbol{A}_{2}\right)$, and hypoxia ( $\left.12 \% \mathrm{FiO}{ }_{2}, \boldsymbol{A}_{3}\right)$. Each panel also depicts the EEG power (FFT, $0-40 \mathrm{~Hz}$ ) recorded during a 30 s window that included the photostimulus period and the preceding $20 \mathrm{~s}$. $\boldsymbol{B}$, Group data (5 rats). $\boldsymbol{B}_{1}$, Light-evoked $\mathrm{f}_{\mathrm{R}}$ reduction during non-REM sleep, quiet wake, and hypoxia (12\% FiO $\boldsymbol{O}_{2}$ ). $\boldsymbol{B}_{2}, \mathrm{~V}_{\mathrm{T}}$ reduction during non-REM sleep, quiet wake, and hypoxia $\left(12 \% \mathrm{FiO}_{2}\right) \cdot \boldsymbol{B}_{\mathbf{3}}, \mathrm{V}_{\mathrm{E}}$ reduction during non-REM sleep, quiet wake, and hypoxia $(12 \% \mathrm{FiO})$. $\boldsymbol{C}$, EEG power ( $0.5-4 \mathrm{~Hz}$ only) during periods of quiet wake in normoxia or during hypoxia expressed as a fraction of the power recorded during periods of non-REM sleep (same 5 rats). ${ }^{*} p<0.05 .{ }^{* *} p<0.01$.

this question, we stimulated RTN neurons optogenetically using a previously described ChR2-expressing lentiviral vector (PRSx8ChR2-EYFP-LVV) (Abbott et al., 2009b) with the same cell specificity as the Arch-delivering vector. ChR2 stimulation increased ventilation at all levels of $\mathrm{FiO}_{2}(N=6$; two-way repeatedmeasures ANOVA; effect of ChR2 stimulation on $\mathrm{f}_{\mathrm{R}}: F_{(1,5)}=$ 37.39, $p=0.002$; Sidak's multiple comparisons: before and after ChR2 stimulation at $21 \%, 15 \%$, and $12 \% \mathrm{FiO}_{2}, p<0.0001$; effect of ChR2 stimulation on $\mathrm{V}_{\mathrm{T}}: F_{(1,5)}=15.87, p=0.01$; Sidak's multiple comparisons: before and after ChR2 at $21 \% \mathrm{FiO}_{2}, p<$ 0.0001 ; at $15 \% \mathrm{FiO}_{2}, p=0.0002$; at $12 \% \mathrm{FiO}_{2}, p=0.002$; effect of ChR2 stimulation on $\mathrm{V}_{\mathrm{E}}: F_{(1,5)}=28.61, p=0.003$; Sidak's multiple comparisons: before and after ChR2 stimulation at $21 \%$, $15 \%$, and $12 \% \mathrm{FiO}_{2}, p<0.0001$ ). The increase in breathing frequency elicited by photostimulation of the ChR2-transduced neurons was slightly reduced by hypoxia (25\% decrease at $12 \%$ $\mathrm{FiO}_{2}$; Fig. $\left.8 \mathrm{~A}, \mathrm{~B}\right)(\mathrm{N}=6$; Friedman one-way repeated-measures ANOVA; effect of photostimulation on $\Delta \mathrm{f}_{\mathrm{R}}$ at different $\mathrm{FiO}_{2}$ : Friedman statistic $=9.333, p=0.006$; Dunn's multiple comparisons: ChR2 stimulation at $21 \%$ vs $12 \% \mathrm{FiO}_{2}, p=0.01$; all other comparisons, $p>0.06$ ). The increase in tidal volume elicited by ChR2 stimulation of RTN was also reduced by hypoxia (50\% on average at $12 \% \mathrm{FiO}_{2}$; Fig. $\left.8 \mathrm{~A}, \mathrm{C}\right)(\mathrm{N}=6$; Friedman one-way repeated-measures ANOVA; effect of photostimulation on $\Delta \mathrm{V}_{\mathrm{T}}$ at different $\mathrm{FiO}_{2}$ : Friedman statistic $=9.333, p=0.006$; Dunn's multiple comparisons: ChR2 stimulation at $21 \%$ vs $12 \% \mathrm{FiO}_{2}$, $p=0.01$; all other comparisons, $p>0.06$ ). Thus, although RTN stimulation did increase breathing at all levels of $\mathrm{FiO}_{2}$, this effect was reduced during hypoxia, by $25 \%$ for $\mathrm{f}_{\mathrm{R}}$ and $50 \%$ for $\mathrm{V}_{\mathrm{T}}$.

\section{Reacidifying the blood restores Arch-triggered hypoventilation during hypoxia}

If RTN neurons are silenced by hypoxia because of respiratory alkalosis, these neurons should be reactivated by blood acidification. This test requires no assumption as to where acidification might ultimately work (RTN, carotid bodies, or other CRCs). Reacidification was achieved by exposing rats to $3 \% \mathrm{FiCO}_{2}$ or by administering the carbonic anhydrase inhibitor acetazolamide, a drug used clinically to stimulate breathing at altitude (Swenson, 2014).

The addition of $3 \% \mathrm{FiCO}_{2}$ to the $12 \%$ hypoxic breathing mixture restored arterial $\mathrm{pH}$ and $\mathrm{PCO}_{2}$ toward the values observed under normoxia, although a very slight respiratory alkalosis persisted ( $\mathrm{pH} 7.48$ vs 7.44; $\mathrm{PaCO}_{2} 34.5$ vs 41.8; Table 1 ). The addition of $\mathrm{CO}_{2}$ also restored Arch-induced bradypnea (Fig. 9A). However, contrary to expectations, $3 \% \mathrm{FiCO}_{2}$ had no effect on the $\mathrm{V}_{\mathrm{T}}$ reduction elicited by RTN inhibition under any of the oxygen concentrations tested (Fig. 9A, $\left.B_{2}\right)(N=5$; two-way repeatedmeasures ANOVA; interaction effect [Arch inhibition $\times$ inhaled gas mixture] on $\mathrm{f}_{\mathrm{R}}: F_{(3,12)}=6.781, p=0.006$; Sidak's multiple comparisons for effects of Arch inhibition on $\mathrm{f}_{\mathrm{R}}$ during $21 \% \mathrm{FiO}_{2}$ vs $21 \% \mathrm{FiO}_{2}+3 \% \mathrm{FiCO}_{2}, p=0.001 ; 15 \% \mathrm{FiO}_{2}$ vs $15 \% \mathrm{FiO}_{2}+$ $3 \% \mathrm{FiCO}_{2}, p=0.005 ; 12 \% \mathrm{FiO}_{2}$ vs $12 \% \mathrm{FiO}_{2}+3 \% \mathrm{FiCO}_{2}, p=$ 0.0009 ; interaction effect [Arch inhibition $\times$ inhaled gas mixture] on $\left.\mathrm{V}_{\mathrm{T}}: F_{(3,12)}=2.413, p=0.1\right)$.

We compared the ventilatory responses to Arch activation following DMSO administration (vehicle for acetazolamide) alone to the responses following acetazolamide. DMSO and acetazolamide were administered to the same 6 rats in random order at an interval of $3 \mathrm{~d}$. In a different cohort of animals $(N=$ 4 ), blood gasses and $\mathrm{pH}$ were measured both before and after acetazolamide administration. Acetazolamide reduced plasma bicarbonate as expected but had no effect on $\mathrm{PCO}_{2}$ regardless of the level of inspired oxygen, except in $65 \% \mathrm{FiO}_{2}$ where there was a slight decrease (Table 1$)(N=4$; two-way repeated-measures ANOVA for acetazolamide and $\mathrm{FiO}_{2}$ on $\mathrm{HCO}_{3}$ : main effect of $\mathrm{FiO}_{2}: F_{(3,9)}=20.08, p=0.0003$; main effect of acetazolamide: $F_{(1,3)}=54.30, p=0.005$; interaction: $F_{(3,9)}=0.9658, p>0.5$; Sidak's multiple comparisons: baseline, $65 \% \mathrm{FiO}_{2}$ vs Acet $65 \%$ $\mathrm{FiO}_{2}, p<0.0001$; baseline, $21 \% \mathrm{FiO}_{2}$ vs Acet $21 \% \mathrm{FiO}_{2}, p=$ 
A1

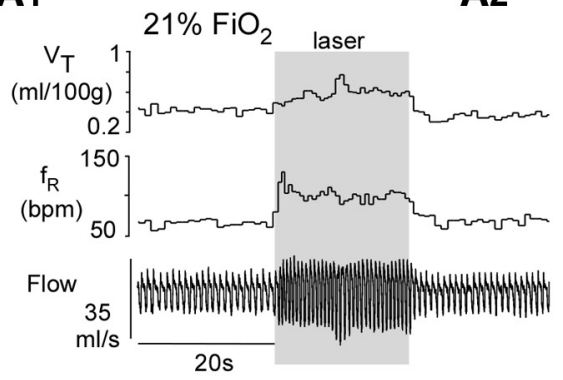

A2

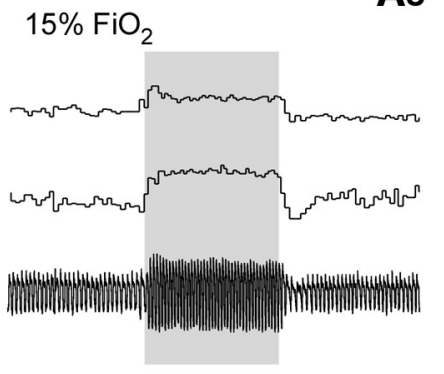

A3

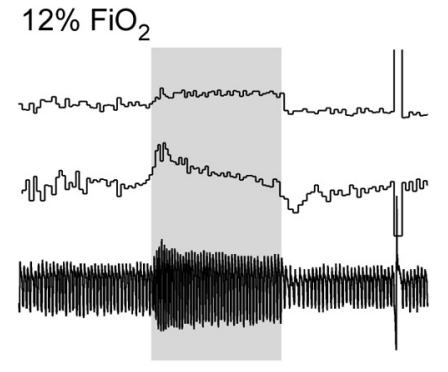

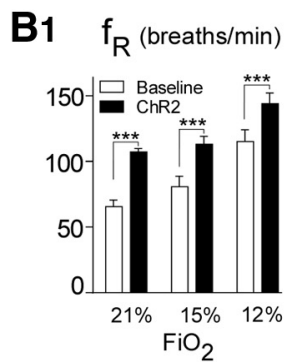

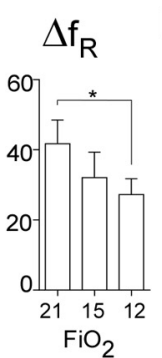

B2 $V_{T}(\mathrm{~m} / 100 \mathrm{~g})$

$\Delta \mathrm{V}_{\mathrm{T}}$

B3
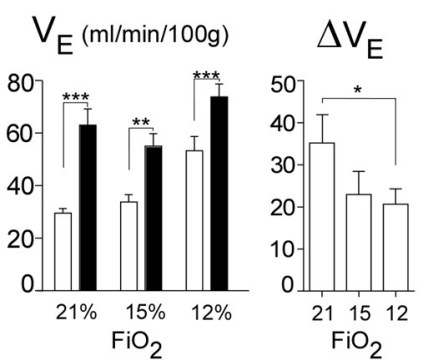

Figure 8. Activation of ChR2-expressing RTN/C1 neurons increases breathing in normoxia and hypoxia. $A$, Hyperventilation caused by unilateral ChR2 photoactivation (20 s, $20 \mathrm{~Hz}, 5 \mathrm{~ms}$ pulse width) in a conscious Sprague Dawley rat under normoxia $\left(21 \% \mathrm{FiO}_{2}, A_{1}\right)$, mild hypoxia $\left(15 \% \mathrm{FiO}_{2}, A_{2}\right)$, and moderate hypoxia $\left(12 \% \mathrm{FiO}_{2}, \boldsymbol{A}_{3}\right) . \boldsymbol{B}$, Left, Ventilation parameters at rest and during ChR2 photostimulation in rats exposed to three different amounts of $\mathrm{O}_{2}$ in the breathing mixture $\left(\mathrm{FiO}_{2}\right)$. Right, Change in ventilation parameters evoked by $\mathrm{ChR2}$ activation $\left(6\right.$ rats). $\boldsymbol{B}_{1}, \mathrm{f}_{\mathrm{R}} \cdot \boldsymbol{B}_{2}, \mathrm{~V}_{\mathrm{T}}$ at rest and during ChR2 photostimulation. $\boldsymbol{B}_{3}, \mathrm{~V}_{\mathrm{E}}$ at rest and during photostimulation ${ }^{*} p<0.05$. ${ }^{* *} p<0.01$. ${ }^{* *} p<0.001$.

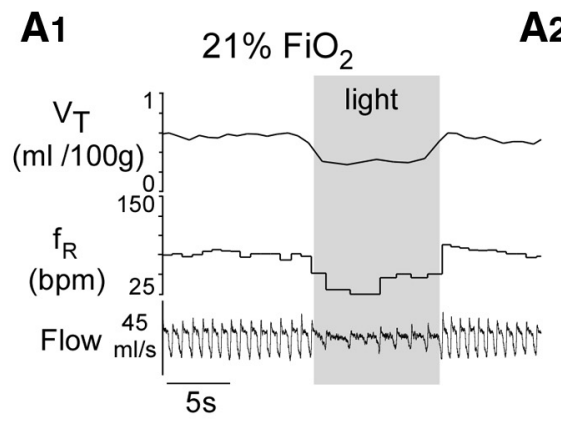

B1

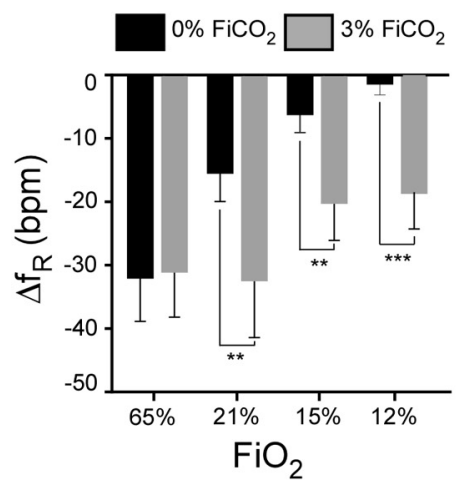

A2

B2
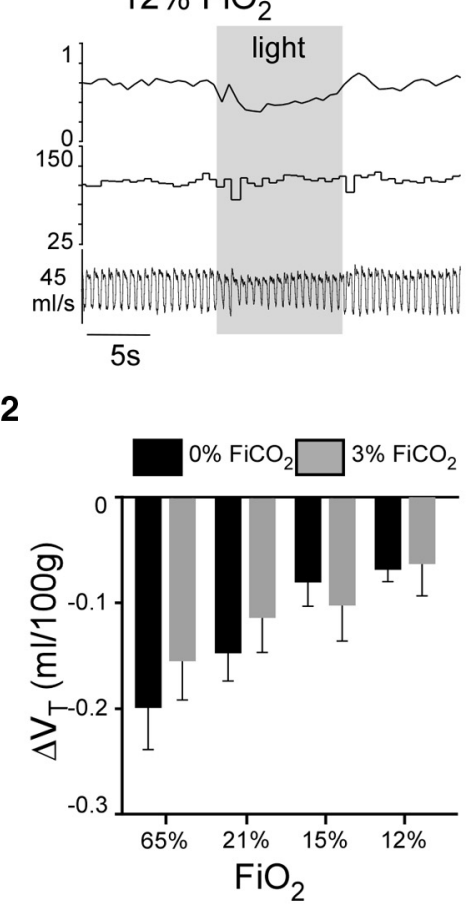

A3

\section{B3}

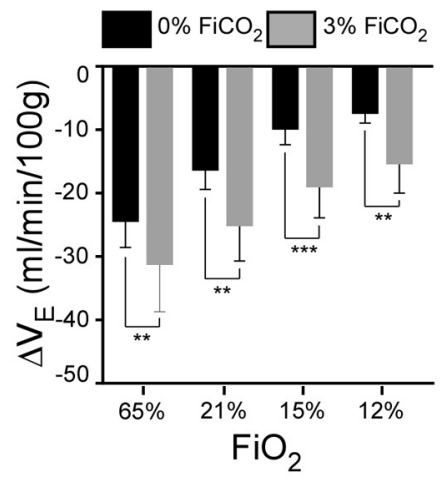

Figure 9. Hypercapnia restores Arch-induced hypoventilation under hypoxia. $\boldsymbol{A}$, Sprague Dawley rat in normoxia $\left(\boldsymbol{A}_{1}, 21 \% \mathrm{FiO}_{2}\right)$, hypoxia $\left(\boldsymbol{A}_{2}, 12 \% \mathrm{FiO} \mathrm{O}_{2}\right)$, and during combined hypoxia and hypercapnia $\left(\boldsymbol{A}_{3}, 12 \% \mathrm{FiO}_{2}+3 \% \mathrm{FiCO}_{2}\right)$. Arch stimulation at gray shaded bars. $\boldsymbol{B}$. Hypoventilation elicited by Arch stimulation as a function of $\mathrm{FiO}_{2}$ and with the addition of $3 \% \mathrm{FiCO}$ : group data $(5$ rats). $\boldsymbol{B}_{1}$, Change in $\mathrm{f}_{\mathrm{R}}$ elicited by Arch photostimulation in the absence or presence of $3 \% \mathrm{FiCO}_{2} \cdot \boldsymbol{B}_{2}$, Change in $\mathrm{V}_{\mathrm{T}}$ elicited by Arch photostimulation in the absence or presence of $3 \% \mathrm{FiCO}_{2} \cdot \boldsymbol{B}_{\mathbf{3}}$, $\mathrm{Change}$ in $\mathrm{V}_{\mathrm{E}}$ elicited by Arch photostimulation in the absence or presence of $3 \% \mathrm{FiCO}_{2} .{ }^{* *} \mathrm{p}<0.01 .{ }^{* * *} \mathrm{p}<0.001$.

0.0007; baseline, $15 \% \mathrm{FiO}_{2}$ and $12 \% \mathrm{FiO}_{2}$ vs Acet, $p=0.0004$; two-way repeated-measures ANOVA for acetazolamide and $\mathrm{FiO}_{2}$ on $\mathrm{PaCO}_{2}$; main effect of $\mathrm{FiO}_{2}, F_{(3,9)}=45.06$, $p<0.0001$; main effect of acetazolamide, $F_{(1,3)}=1.398, p=0.3$; interaction, $F_{(3,9)}$ $=5.767, p=0.02$; Sidak's multiple comparisons: baseline, $65 \%$
$\mathrm{FiO}_{2}$ vs Acet $65 \% \mathrm{O}_{2}, p=0.002$; baseline, $21 \% \mathrm{FiO}_{2}, 15 \% \mathrm{FiO}_{2}$, and $12 \% \mathrm{FiO}_{2}$ vs Acet $21 \% \mathrm{FiO}_{2}, 15 \% \mathrm{FiO}_{2}$, and $12 \% \mathrm{FiO}_{2}, p>$ 0.2 ). Acetazolamide lowered $\mathrm{pHa}$ significantly at all levels of $\mathrm{FiO}_{2}$, except $65 \%$, and greatly reduced the alkalization resulting from hypoxia (two-way repeated-measures ANOVA for acet- 


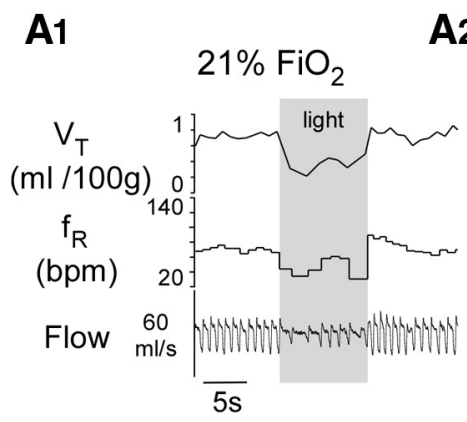

B1

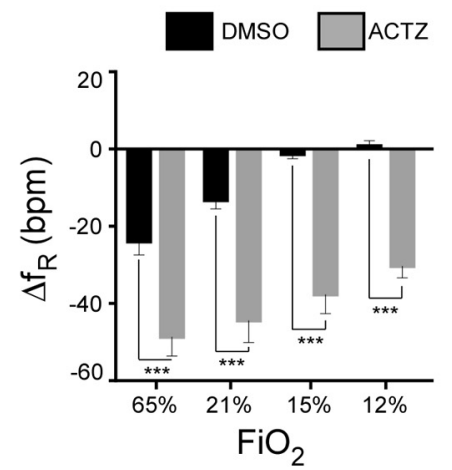

A2

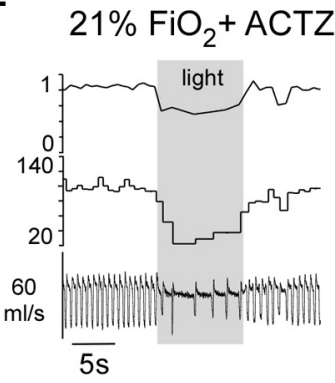

B2

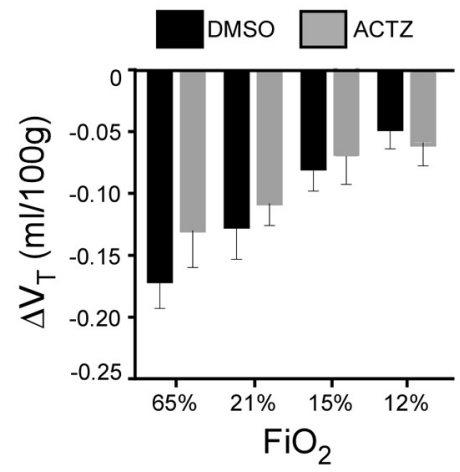

A3

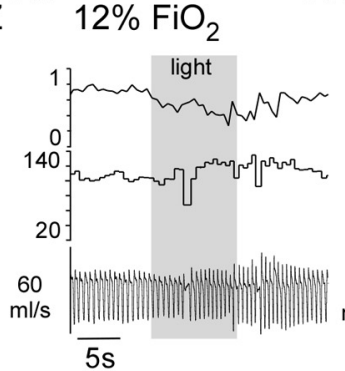

B3

A4
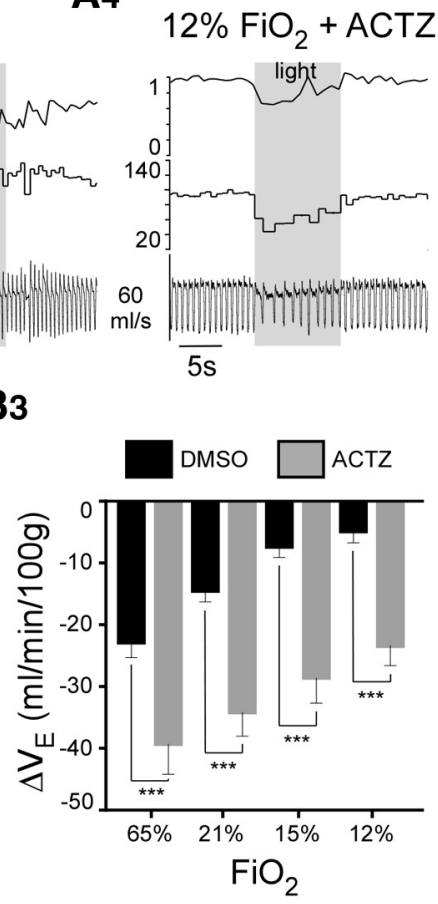

Figure 10. Acetazolamide (ACTZ) restores Arch-induced hypoventilation under hypoxia. $A_{1}, A_{2}$, Sprague Dawley rat under normoxia $\left(21 \% \mathrm{Fi} \mathrm{O}_{2}\right)$ treated with DMSO $\left(A_{1}\right.$, control) or $\mathrm{ACTZ}\left(\boldsymbol{A}_{2}\right)$. Arch activation with laser light during gray shaded regions. $A_{3}, A_{4}$, Same rat under hypoxia $\left(12 \% \mathrm{FiO}_{2}\right)$ after DMSO $\left(\boldsymbol{A}_{3}\right)$ or ACTZ $\left(\boldsymbol{A}_{4}\right)$. $\boldsymbol{B}$, Group data $(N=6$, Control $=7)$. $\boldsymbol{B}_{1}$, Reduction in $\mathrm{f}_{\mathrm{R}}$ elicited by Arch activation at different $\mathrm{FiO}_{2}$ in control (DMSO) and $\mathrm{ACTZ}$-treated rats. $\boldsymbol{B}_{2}$, Reduction in $\mathrm{V}_{\mathrm{T}}$ elicited by Arch activation at different $\mathrm{FiO}_{2}$ in control (DMSO) and ACTZ-treated rats. $\boldsymbol{B}_{3}$, Reduction of $\mathrm{V}_{\mathrm{E}}$ elicited by Arch activation at different $\mathrm{FiO}_{2}$ in control (DMSO) and $\mathrm{ACTZ}$-treated rats. ${ }^{* *} \mathrm{p}<0.001$.

azolamide and $\mathrm{FiO}_{2}$ on $\mathrm{pH}$; main effect of $\mathrm{FiO}_{2}: F_{(3,9)}=285.1$, $p<0.0001$; main effect of acetazolamide: $F_{(1,3)}=77.84, p=$ 0.003; interaction: $F_{(3,9)}=17.39, p=0.0004$; Sidak's multiple comparisons: baseline, $65 \% \mathrm{FiO}_{2}$ vs Acet $65 \% \mathrm{FiO}_{2}, p=0.09$; baseline, $21 \% \mathrm{FiO}_{2}$ vs Acet $21 \% \mathrm{FiO}_{2}, p=0.004$; baseline, $15 \%$ $\mathrm{FiO}_{2}$ and $12 \% \mathrm{FiO}_{2}$ vs Acet $15 \% \mathrm{FiO}_{2}$ and $\left.12 \% \mathrm{FiO}_{2}, p<0.0001\right)$.

Arch-induced bradypnea $\left(\Delta \mathrm{f}_{\mathrm{R}}\right)$ was strongly dependent on $\mathrm{FiO}_{2}$ in the control group (DMSO, Fig. 10; $N=6$; one-way repeated-measures ANOVA; effect of $\mathrm{FiO}_{2}$ on $\mathrm{f}_{\mathrm{R}}: F_{(1,5)}=34.12$, $p=0.0005)$. Acetazolamide increased resting ventilation under all oxygen conditions (not illustrated; $N=6$; two-way repeatedmeasures ANOVA for $\mathrm{f}_{\mathrm{R}}$; main effect of acetazolamide: $F_{(1,5)}=$ $364.7, p<0.0001)$. After administration of acetazolamide, Archinduced bradypnea was observed under all oxygen conditions tested (Fig. 10A,B) ( $N=6$; two-way repeated-measures ANOVA; main effect of Arch on $\mathrm{f}_{\mathrm{R}}: F_{(1,5)}=87.07, p=0.0002$. Sidak's multiple comparisons: baseline vs Arch for $65 \%, 21 \%$, $15 \% \mathrm{FiO}_{2}$, and $\left.12 \% \mathrm{FiO}_{2}, p<0.0001\right)$. However, as in the $\mathrm{CO}_{2}$ supplementation experiments, acetazolamide restored only the decrease in frequency evoked by inhibiting RTN (Fig. 10A $A_{4} B_{1}$ ) $(N=6$; two-way repeated-measures ANOVA; main effect of acetazolamide on $\left.\mathrm{f}_{\mathrm{R}}: F_{(1,5)}=93.01, p=0.0002\right)$ but had no effect on the $V_{T}$ reduction elicited by RTN inhibition under any of the oxygen concentrations tested (Fig. $\left.10 A_{4}, B_{2}\right)(N=6$; two-way repeated-measures ANOVA, main effect of acetazolamide on $\mathrm{V}_{\mathrm{T}}$ : $F_{(15)}=4.08, p=0.09$, Sidak's multiple comparisons: all comparisons, $p>0.1$ ).

In summary, during hypoxia, blood reacidification produced by increasing $\mathrm{FiCO}_{2}$ or by injection of acetazolamide restored the ability of RTN inhibition to reduce the respiratory frequency, but acidification had no detectable influence on the concomitant reduction of breathing amplitude elicited by RTN inhibition.
Relationship between $\mathrm{pHa}, \mathrm{PaCO}_{2}$, and the breathing stimulation contributed by Arch-transduced RTN neurons To test the contribution of pHa and $\mathrm{PaCO}_{2}$ to RTN neuron activity in conscious rats, we analyzed the relationship between $\Delta \mathrm{f}_{R}$, $\Delta \mathrm{V}_{\mathrm{T}}$, and $\Delta \mathrm{V}_{\mathrm{E}}$ elicited by inhibiting Arch-transduced RTN neurons and $\mathrm{pHa}$ or $\mathrm{PaCO}_{2}$ under the nine conditions examined $\left(65 \%, 21 \%, 15 \%\right.$, and $12 \% \mathrm{FiO}_{2}$, under control conditions, in the presence of $3 \% \mathrm{FiCO}_{2}$, and in the presence of acetazolamide). The $\mathrm{pHa}$ and $\mathrm{PCO}_{2}$ values used for the linear regression analysis were the mean blood gas values shown in Table 1 , and the mean values of $\Delta \mathrm{f}_{\mathrm{R}}, \Delta \mathrm{V}_{\mathrm{T}}$ and $\Delta \mathrm{V}_{\mathrm{E}}$ recorded for each of the 9 groups.

There was an extremely tight inverse correlation between $\Delta \mathrm{f}_{\mathrm{R}}$ and $\mathrm{pHa}(N=9$; Pearson $r=0.93, p<0.0002$; Fig. $11 A)$ but no correlation between $\Delta \mathrm{f}_{\mathrm{R}}$ and $\mathrm{PaCO}_{2}$ (Pearson $r=-0.44, p=0.2$; Fig. 11A). Interestingly, the correlations were reversed for $\Delta \mathrm{V}_{\mathrm{T}}$. This variable was not correlated with $\mathrm{pHa}$ (Pearson $r=0.41, p=$ 0.3 ; Fig. $11 B)$ but very highly correlated with $\mathrm{PaCO}_{2}$ (Pearson $r=$ $-0.91, p=0.0007$; Fig. $11 E) . \Delta \mathrm{V}_{\mathrm{E}}$, which predominantly reflects changes in breathing frequency, was, as expected, highly correlated with $\mathrm{pHa}$ (Pearson $r=0.93, p<0.0003$; Fig. 11C), but not with $\mathrm{PaCO}_{2}$ (Pearson $r=-0.49, p=0.2$; Fig. $11 F$ ). The reason why $\Delta \mathrm{f}_{\mathrm{R}}$ was not correlated with $\mathrm{PaCO}_{2}$ and $\Delta \mathrm{V}_{\mathrm{T}}$ to $\mathrm{pHa}$ became clearer when we plotted separately the results obtained with or without acetazolamide treatment. It then became apparent that the relationship between $\Delta \mathrm{f}_{\mathrm{R}}$ and $\mathrm{PaCO}_{2}$ was also linear (due to the limited number of points, no statistical test was applied) but consisted of two parallel regression lines corresponding to the presence or absence of acetazolamide (Fig. 11D). Similarly, the relationship between $\Delta \mathrm{V}_{\mathrm{T}}$ and $\mathrm{pHa}$ consisted of two parallel regression lines (Fig. 11B). Acetazolamide increases renal bicarbonate excretion; consequently, this drug lowers plasma bicarbonate considerably (Table 1). Acetazolamide must there- 
A
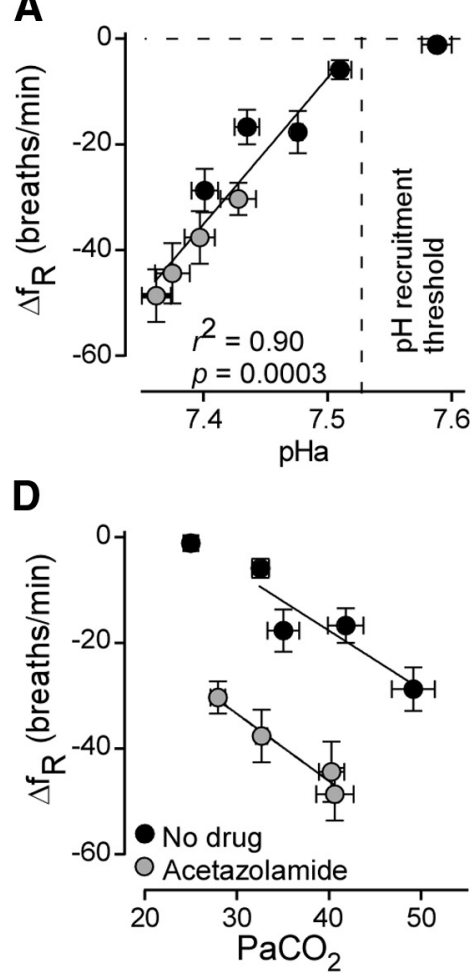

B

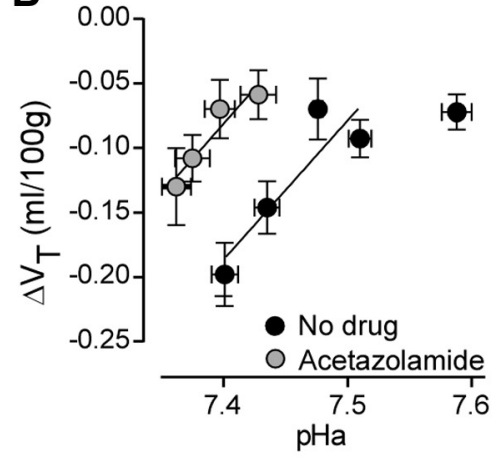

E

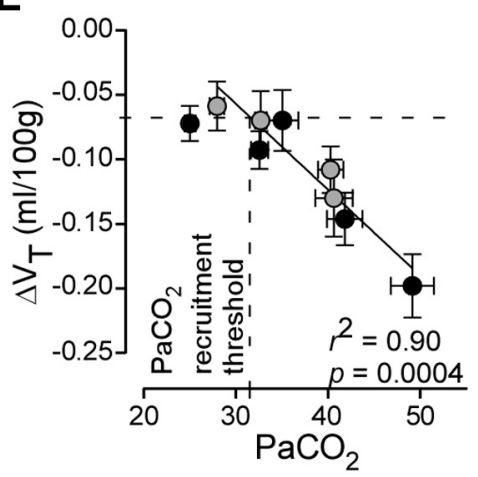

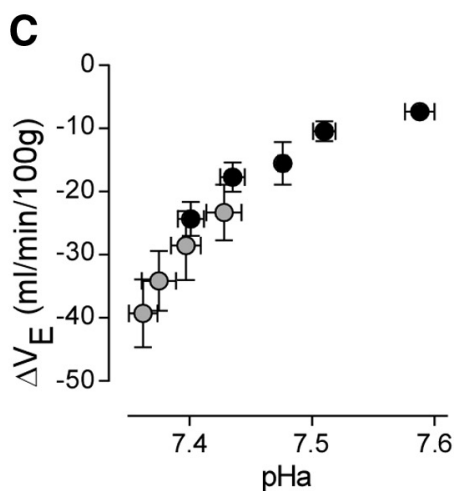

$\mathbf{F}$

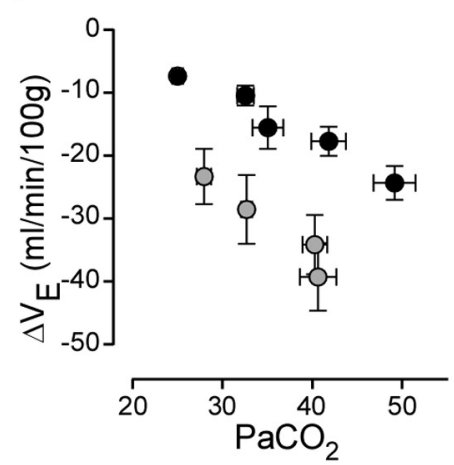

Figure 11. Relationship between arterial pH or $\mathrm{PaCO}_{2}$ and breathing drive contributed by Arch-transduced RTN neurons. $A-C, x-y$ plots of pHa versus Arch-induced reductions in $\Delta \mathrm{f}_{\mathrm{R}^{\prime}} \Delta \mathrm{V}_{\mathrm{T}^{\prime}}$ and $\Delta \mathrm{V}_{\mathrm{E}}$. Gray-filled circles represent data from acetazolamide-treated rats. Black-filled circles represent data from drug-free rats. $\boldsymbol{D}-\boldsymbol{F}$, Plots of $\mathrm{PaCO}_{2}$ versus Arch-induced $\Delta \mathrm{f}_{\mathrm{R}}, \Delta \mathrm{V}_{\mathrm{T}}$, and $\mathrm{V}_{\mathrm{E}}$. Note the tight linear relationships between $\Delta \mathrm{f}_{\mathrm{R}}$ and pHa and between $\Delta \mathrm{V}_{\mathrm{T}}$ and $\mathrm{PaCO}_{2}$ across all experimental conditions. The calculated pH recruitment threshold (i.e., pHa below which RTN is active) was 7.53. This value was determined by the intersection of the regression line and the zero horizontal line $(\boldsymbol{A})$. The data point at $12 \% \mathrm{FiO}_{2}$ (no drug) was excluded from the linear regression analysis because $\Delta \mathrm{f}_{\mathrm{R}}$ was zero and pHa (7.6) was clearly beyond the recruitment threshold. The $\mathrm{PaCO}_{2}$ recruitment threshold (i.e., PaC $\mathrm{O}_{2}$ above which RTN becomes active) was $32 \mathrm{mmHg}$. This value was obtained from $E$ as the intersection between the linear part of the regression curve and the plateau defined by the invariant values of $\Delta \mathrm{V}_{T}$ measured at PaC $\mathrm{O}_{2}$ values below the estimated recruitment threshold (E). Physiological data: four levels of $\mathrm{FiO}_{2}(N=9), 12 \% \mathrm{FiO}_{2}$ with $3 \% \mathrm{FiCO}_{2}(N=7)$, four levels of FiO with acetazolamide $(N=6)$. Arterial blood gas: four levels of $\mathrm{FiO}_{2}(N=6), 12 \% \mathrm{FiO}_{2}$ with $3 \% \mathrm{FiCO}_{2}(\mathrm{~N}=4)$, four levels of $\mathrm{FiO}_{2}$ with acetazolamide $(\mathrm{N}=4)$.

fore change the relationship between $\mathrm{pH}$ and $\mathrm{PCO}_{2}$ according to the local bicarbonate concentration. This relationship is likely to be different within the environment of the CRCs than in the carotid bodies, which are bathed by the plasma. The existence of two parallel regression lines for the relationship between $\Delta \mathrm{V}_{\mathrm{T}}$ and $\mathrm{pHa}$ and $\Delta \mathrm{f}_{\mathrm{R}}$ and $\mathrm{PaCO}_{2}$ could be related to the relative contribution of CRCs and the CBs to RTN neuron activity.

A recruitment threshold (the level at which RTN neurons start to be active) for $\mathrm{pHa}$ and $\mathrm{PaCO}_{2}$ was determined from the regression lines by postulating that these neurons were silent when Arch activation no longer changed $\mathrm{f}_{\mathrm{R}}$ (Fig. 11A) or when Arch activation reduced $\mathrm{V}_{\mathrm{T}}$ by an amount that was unchanged by further acidification or a further increase in $\mathrm{PaCO}_{2}$ (e.g., Fig. 11E). A $\mathrm{pHa}$ recruitment threshold of 7.53 and $\mathrm{PaCO}_{2}$ recruitment threshold of $32 \mathrm{mmHg}\left(\sim 4.2 \% \mathrm{CO}_{2}\right)$ could thus be calculated (Fig. 11 A,E, hatched line). These values are virtually identical to the recruitment threshold of RTN neurons recorded in anesthetized animals (present results; Guyenet et al., 2005). The presence of a small pH- and $\mathrm{PCO}_{2}$-independent $\Delta \mathrm{V}_{\mathrm{T}}(\sim 0.07 \mathrm{ml} / 100 \mathrm{~g}$; Fig. $11 B, E)$ has several potential explanations. $\mathrm{V}_{\mathrm{T}}$-regulating RTN neurons may not be completely silenced by alkalization in conscious animals or this residual $V_{T}$ reduction could result from the inhibition of Arch-transduced neurons that are not RTN neurons (e.g., the $\mathrm{C} 1$ cells).

In summary, this analysis shows that RTN activity tracks $\mathrm{pHa}$ and/or $\mathrm{PaCO}_{2}$ independently of the intensity of breathing over a wide variety of experimental conditions.

\section{Discussion}

We report several new findings: inhibiting RTN and nearby C1 neurons reduces ventilation equally during non-REM sleep and quiet waking. The hypoventilation is largest during hyperoxia, virtually eliminated during hypocapnic hypoxia, and reinstated under isocapnic hypoxia. The hypoventilation is highly correlated with $\mathrm{pHa}$ or $\mathrm{PaCO}_{2}$. The most plausible interpretation is that, in sleeping or quietly awake rats, RTN neurons stimulate breathing in proportion to the degree of acidification below a threshold of $7.5 \mathrm{pHa}$. C1 neuron inhibition is unlikely to have contributed to the hypoventilation, but this possibility is not entirely excluded.

\section{Technical and interpretative limitations}

Under anesthesia, Arch activation silenced RTN neurons even in the presence of $10 \% \mathrm{eeCO}_{2}$. Thus, the proton pump overcame any cell-autonomous or astrocyte-dependent activation of RTN caused by hypercarbia via protons or molecular $\mathrm{CO}_{2}$ (Gourine et al., 2008; Huckstepp et al., 2010; Wang et al., 2013a). Extrapolating this finding to conscious rats seems legitimate because illumination of Arch-transduced versus ChR2-transduced RTN neurons produced opposite effects, both at the single-unit and system levels (Abbott et al., 2009b).

$\mathrm{C} 1$ cell activation raises both $\mathrm{BP}$ and ventilation (Abbott et al., 2013; Guyenet et al., 2013). Therefore, inhibition of Archtransduced $\mathrm{C} 1$ neurons could have contributed to the lightevoked hypoventilation. However, if this contribution had been 
Normoxia

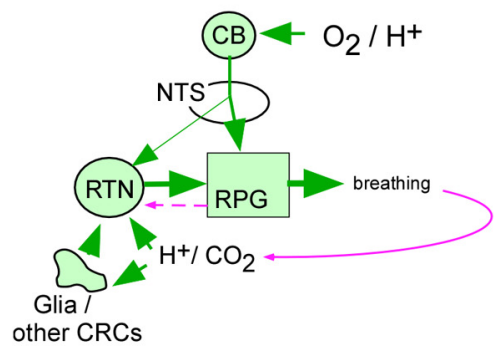

Hypoxia

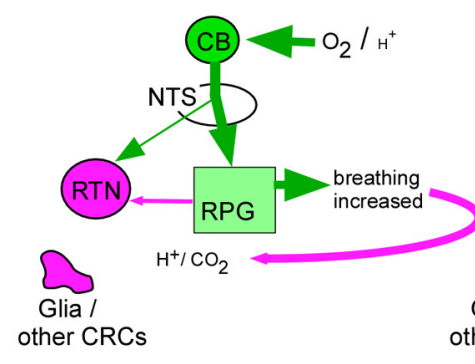

Hyperoxia

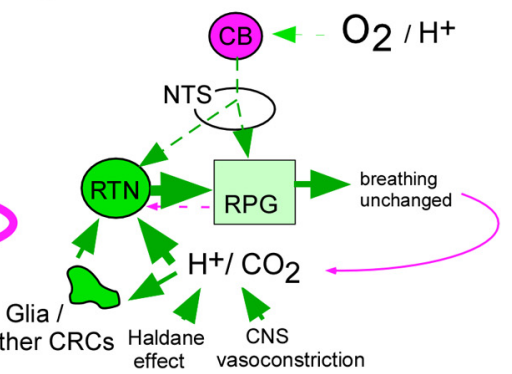

Figure 12. Summary and interpretations. During eupnea (regular involuntary breathing as during non-REM sleep and quiet wake), breathing rate and amplitude are generated by a network of pontomedullary structures called the respiratory pattern generator (RPG). Under normoxia, eupneic breathing is activated by inputs (green arrows) from RTN and from the (Bs. The CB pathway relays in the nucleus of the solitary tract (NTS). The (Bs activate breathing via RTN and independently of RTN. RTN neurons are subject to several feedback regulations (pink lines). At rest, the most powerful regulation of $\mathrm{RPG}$ operates via $\mathrm{CO}_{2} / \mathrm{pH}$. Alkalization caused by hyperventilation withdraws the direct and astrocyte-dependent excitatory effect of acid on RTN neurons. Alkalization may also reduce excitatory inputs to RTN from other CNS acid-activated neurons and activate inhibitory inputs from unidentified acid-inhibited CNS neurons. Additional feedback (pink lines) originates from lung stretch receptors (not illustrated) and the RPG (illustrated) and may protect the lungs against hyperinflation. During hypocapnic hypoxia, the CBs are highly active, drive the RPG vigorously, which increases breathing and lowers $\mathrm{PaCO}_{2}$ and arterial $\left[\mathrm{H}^{+}\right.$]. The increased ventilation further activates the inhibitory feedback to $\mathrm{RTN}$ (solid pink lines) causing these cells to become silent. The chemical feedback (via alkalization of RTN) is the most powerful and causes RTN neurons to become silent under hypoxia despite increased excitatory input from the (Bs. During hyperoxia, the CBs are inactive, but $\mathrm{CNS}\left[\mathrm{H}^{+}\right.$] and $\mathrm{PCO}_{2}$ increase because ventilation is reduced (in rats only) and because hyperoxia reduces cerebral blood flow and facilitates $\mathrm{CO}_{2}$ dumping from erythrocytes (Haldane effect). The resulting brain acidification activates RTN further; and because of the loss of the respiratory drive that originates from the CBs, RTN contributes a much larger portion of the respiratory drive than under normoxia. Green arrows indicate excitatory pathways or stimulatory effects. Dashed lines indicate weak inputs. Solid lines of increasing thickness indicate stronger input. Pink arrows indicate inhibitory pathways or feedback (intensity also coded with dashes and lines of increasing thickness). Pale green circles or boxes represent moderately active cell groups. Dark green represents high activity. Pink represents inactivity (as in CBs during hyperoxia).

substantial, hypoventilation should have been greater during hypoxia, not smaller as observed, because $\mathrm{C} 1$ cells are strongly activated by hypoxia (Sun and Reis, 1996). Moreover, there was only a weak correlation between hypoventilation and the number of Arch-transduced catecholaminergic neurons located close to the optical fiber.

Under anesthesia, RTN neurons were silenced regardless of eeCO ${ }_{2}(4 \%-10 \%$, corresponding to $7.5-7.2 \mathrm{pHa}$ ) (Guyenet et al., 2005). A pH-dependent change in proton pump efficacy is therefore unlikely to explain the inability of Arch activation to reduce breathing during hypoxia.

Astrocytes did not express Phox $2 \mathrm{~b}$ and did not contain histologically detectable levels of Arch; therefore, these cells were presumably not directly affected by light. Conceivably, astrocytes could have been depolarized by Arch-induced extracellular acidification (Chow et al., 2010; Mulkey and Wenker, 2011). The ensuing ATP release (Gourine et al., 2010) could possibly have attenuated the light-induced inhibition of RTN neurons.

\section{RTN drives resting breathing}

Whether RTN neurons drive breathing in resting conscious mammals is controversial. Li et al. (1999) concluded that RTN stimulation with $\mathrm{CO}_{2}$ increases $\mathrm{V}_{\mathrm{T}}$ in awake rats only, and Marina et al. (2010) found that RTN inhibition did not change resting ventilation. Yet, muscimol injections into RTN reduce breathing (Li et al., 2006; Takakura et al., 2013) and genetic deletion of RTN produces resting hypoventilation (Ramanantsoa et al., 2011).

Unlike other approaches, the Arch method measures the instantaneous contribution of RTN neurons to breathing with minimal interference from homeostatic compensations (CBs, other CRCs). Our results show that RTN Phox2b-expressing neurons drive resting ventilation equally during non-REM sleep and quiet waking.

Congenital central hypoventilation syndrome is tentatively attributed to Phox $2 \mathrm{~b}$ mutations that abort RTN development (Pattyn et al., 1999; Amiel et al., 2003, 2009; Goridis and Brunet, 2010; Weese-Mayer et al., 2010; Ramanantsoa et al., 2011). Sleep apnea, the defining feature of congenital central hypoventilation syn- drome, occurs mostly during non-REM sleep. Our finding that RTN sustains breathing during non-REM sleep supports this theory.

\section{RTN neurons encode $\mathrm{pHa} / \mathrm{PaCO}_{2}$}

Without acetazolamide, $\Delta \mathrm{f}_{\mathrm{R}}$ and $\Delta \mathrm{V}_{\mathrm{T}}$ were correlated with both $\mathrm{pHa}$ and $\mathrm{PaCO}_{2}$. The $\mathrm{pHa}$ and $\mathrm{PaCO}_{2}$ levels at which $\Delta \mathrm{f}_{\mathrm{R}}$ was 0 (7.53) or $\Delta \mathrm{V}_{\mathrm{T}}$ was independent of further reduction in $\mathrm{PaCO}_{2}(32$ $\mathrm{mmHg}$ ) indicate when RTN neurons are silent ("recruitment threshold"). These values were very close to those measured in anesthetized rats by unit recording (Guyenet et al., 2005; present results). Thus, $\mathrm{pH}$ and/or $\mathrm{PaCO}_{2}$ are the principal determinants of RTN activity under hypoxic, normoxic, or hyperoxic conditions in conscious resting rats.

RTN Phox $2 \mathrm{~b}$ neurons are prominent $\mathrm{CRC}$ candidates because they are activated by hypercarbia in vivo and are intrinsically acid-sensitive, their activation increases breathing, and deletion of the acid-sensitive channel TASK-2 from these neurons greatly reduces both their $\mathrm{pH}$ sensitivity and the hypercapnic chemoreflex (Gestreau et al., 2010; Guyenet et al., 2010; Wang et al., 2013b).

The tight relationship between RTN neuron activity and arterial $\mathrm{pH} / \mathrm{PCO}_{2}$ is consistent with their $\mathrm{CRC}$ properties, but this $\mathrm{pH}$ sensitivity could also derive from surrounding astrocytes and input from other $\mathrm{pH}$-responsive neurons (Deng et al., 2007; Williams et al., 2007; Dias et al., 2009; Gourine et al., 2010; Huckstepp et al., 2010; Corcoran et al., 2013; Iceman et al., 2013; Li et al., 2013).

\section{RTN neurons: first putative CRCs demonstrably silenced by hypocapnic hypoxia}

The hypothesis that hypoxia inhibits CRCs via respiratory alkalosis is long-standing (Gesell et al., 1940). Yet, we show here the first example of putative CRCs inhibited by hypocapnic hypoxia. The key evidence is that RTN photoinhibition no longer inhibited $\mathrm{f}_{\mathrm{R}}$ during hypoxia unless the plasma was reacidified with $\mathrm{CO}_{2}$ or acetazolamide (Peña and García, 2006; Bell and Haouzi, 2010). Importantly, the difference between hypoxia and normoxia was 
neither related to hypoxia-induced arousal nor caused by the inability of RTN neurons to drive breathing under hypoxia because activation of ChR2-transduced RTN neurons increased $f_{R}$ massively during hypoxia.

\section{CB stimulation can activate $f_{R}$ via pathways that bypass RTN} Convergence between central and peripheral chemoreceptors on a unique set of neurons that ultimately regulate the respiratory pattern generator has long been hypothesized (Gesell et al., 1940; Loeschcke, 1982; Smith et al., 2010). Although RTN receives an excitatory input from the CBs (Takakura et al., 2006), RTN is not an obligatory relay for the peripheral chemoreflex (Fig. 12) because hypocapnic hypoxia increased $\mathrm{f}_{\mathrm{R}}$ while silencing RTN neurons. The fact that the powerful excitatory input from $\mathrm{CBs}$ to RTN is suppressed by alkalization further stresses the importance of $\mathrm{pH}$ as a regulator of $\mathrm{RTN}$ activity.

CB second-order neurons and RTN neurons target multiple brainstem regions (Koshiya and Guyenet, 1996; Song et al., 2011; Bochorishvili et al., 2012). Integration between central and peripheral chemoreflexes likely occurs both within and outside RTN.

\section{RTN is activated by hyperoxia}

$\mathrm{CBs}$ contribute greatly to resting ventilation, even in normoxia (Olson et al., 1988; Forster et al., 2008; Smith et al., 2010). Although hyperoxia silences the $\mathrm{CBs}$, ventilation is barely decreased in rats (present results; Olson et al., 1988) or mildly stimulated in humans (Becker et al., 1996; Ainslie and Duffin, 2009; Chowdhuri et al., 2010). Our results provide a potential explanation for this paradox (Fig. 12): hyperoxia activates RTN and the increased breathing stimulation contributed by this nucleus compensates (rats) or perhaps overcompensates (humans) for the reduced CB activity. This interpretation stems from the observation that, in conscious rats, silencing RTN produced a much larger hypoventilation in hyperoxia than normoxia.

Correlative evidence (Fig. 11) suggests that hyperoxia increases RTN activity largely via respiratory acidosis (reduced pHa and increased $\mathrm{PaCO}_{2}$ ). However, hyperoxia also acidifies the CNS via the Haldane effect and CNS vasoconstriction (Becker et al., 1996; Ainslie and Duffin, 2009; Chowdhuri et al., 2010). In humans, these alternative mechanisms presumably dominate because breathing is slightly activated by hyperoxia and respiratory alkalosis ensues (Becker et al., 1996).

\section{Differential effect of pHa vs $\mathrm{PaCO}_{2}$ on RTN activity}

Without acetazolamide, $\Delta \mathrm{f}_{\mathrm{R}}$ and $\Delta \mathrm{V}_{\mathrm{T}}$ were correlated with both $\mathrm{pHa}$ and $\mathrm{PaCO}_{2}$ regardless of the level of $\mathrm{FiO}_{2}$ or $\mathrm{FiCO}_{2}$. Therefore, $\mathrm{CO}_{2} / \mathrm{pH}$-responsive $\mathrm{RTN}$ neurons regulate both breathing rate and amplitude. This is consistent with prior evidence. Activation of ChR2-transduced Phox2b RTN neurons increases $f_{R}$ and $\mathrm{V}_{\mathrm{T}}, \mathrm{CO}_{2}$ dialysis into $\mathrm{RTN}$ increases $\mathrm{V}_{\mathrm{T}}$ (Li et al., 1999), and virtually all Phox2b RTN neurons respond to $\mathrm{H}^{+} / \mathrm{CO}_{2}$ in vitro (Lazarenko et al., 2009).

When the data collected during metabolic acidosis (acetazolamide) were incorporated, $\Delta f_{R}$ remained correlated with $\mathrm{pHa}$ but was no longer correlated with $\mathrm{PaCO}_{2}$, whereas the reverse occurred for $\Delta \mathrm{V}_{\mathrm{T}}$. This could mean that distinct RTN neurons control $\mathrm{f}_{\mathrm{R}}$ versus $\mathrm{V}_{\mathrm{T}}$. Many $\mathrm{RTN}$ neurons receive strong polysynaptic excitatory input from the CBs (Takakura et al., 2006). Under metabolic acidosis, the activity of these neurons may remain better correlated with $\mathrm{pHa}$ simply because the $\mathrm{CBs}$ encode $\mathrm{pHa}$. These particular neurons may regulate $f_{R}$ preferentially because CB stimulation (hypoxia) increases $f_{R}$ selectively. The $V_{T^{-}}$ regulating RTN neurons may respond predominantly to changes in $\mathrm{CNS} \mathrm{pH}$ and may receive less $\mathrm{CB}$ input. If, after acetazolamide, the bicarbonate concentration were to remain higher in brain than in plasma, the activity of these RTN neurons would still track $\mathrm{PaCO}_{2}$ because $\mathrm{CO}_{2}$ is diffusible, but it would no longer correlate with $\mathrm{pHa}$, as observed, because brain $\mathrm{pH}$ would be far less acidic. An alternative explanation is that $\mathrm{V}_{\mathrm{T}}$-regulating $\mathrm{RTN}$ neurons respond preferentially to molecular $\mathrm{CO}_{2}$ (Huckstepp et al., 2010).

\section{Pathophysiological implications}

Hypoxia and conditions in which CBs are hyperactive (congestive heart failure, hypertension) cause sleep apnea and/or periodic breathing (McBryde et al., 2013; Schultz et al., 2013; Dempsey et al., 2014). Judging from the present study, CB hyperactivity should reduce RTN contribution to breathing. According to established reasoning, reduced CCR activity should promote apneas or periodic breathing (Ainslie and Duffin, 2009; Cui et al., 2012; Javaheri and Dempsey, 2013). Our results also account for the therapeutic benefits of mild hypercapnia and acetazolamide in hypoxia and congestive heart failure (Sharma et al., 2011).

\section{References}

Abbott SB, Stornetta RL, Socolovsky CS, West GH, Guyenet PG (2009a) Photostimulation of channelrhodopsin-2 expressing ventrolateral medullary neurons increases sympathetic nerve activity and blood pressure in rats. J Physiol 587:5613-5631. CrossRef Medline

Abbott SB, Stornetta RL, Fortuna MG, Depuy SD, West GH, Harris TE, Guyenet PG (2009b) Photostimulation of retrotrapezoid nucleus phox $2 \mathrm{~b}$-expressing neurons in vivo produces long-lasting activation of breathing in rats. J Neurosci 29:5806-5819. CrossRef Medline

Abbott SB, Stornetta RL, Coates MB, Guyenet PG (2011) Phox2bexpressing neurons of the parafacial region regulate breathing rate, inspiration, and expiration in conscious rats. J Neurosci 31:16410-16422. CrossRef Medline

Abbott SB, Kanbar R, Bochorishvili G, Coates MB, Stornetta RL, Guyenet PG (2012) C1 neurons excite locus coeruleus and A5 noradrenergic neurons along with sympathetic outflow in rats. J Physiol 590:2897-2915. CrossRef Medline

Abbott SB, DePuy SD, Nguyen T, Coates MB, Stornetta RL, Guyenet PG (2013) Selective optogenetic activation of rostral ventrolateral medullary catecholaminergic neurons produces cardiorespiratory stimulation in conscious mice. J Neurosci 33:3164-3177. CrossRef Medline

Ainslie PN, Duffin J (2009) Integration of cerebrovascular $\mathrm{CO}_{2}$ reactivity and chemoreflex control of breathing: mechanisms of regulation, measurement, and interpretation. Am J Physiol Regul Integr Comp Physiol 296:R1473-R1495. CrossRef Medline

Ainslie PN, Lucas SJ, Burgess KR (2013) Breathing and sleep at high altitude. Respir Physiol Neurobiol 188:233-256. CrossRef Medline

Amiel J, Laudier B, Attié-Bitach T, Trang H, de Pontual L, Gener B, Trochet D, Etchevers H, Ray P, Simonneau M, Vekemans M, Munnich A, Gaultier C, Lyonnet S (2003) Polyalanine expansion and frameshift mutations of the paired-like homeobox gene PHOX2B in congenital central hypoventilation syndrome. Nat Genet 33:459-461. CrossRef Medline

Amiel J, Dubreuil V, Ramanantsoa N, Fortin G, Gallego J, Brunet JF, Goridis C (2009) PHOX2B in respiratory control: lessons from congenital central hypoventilation syndrome and its mouse models. Respir Physiol Neurobiol 168:125-132. CrossRef Medline

Aravanis AM, Wang LP, Zhang F, Meltzer LA, Mogri MZ, Schneider MB, Deisseroth K (2007) An optical neural interface: in vivo control of rodent motor cortex with integrated fiberoptic and optogenetic technology. J Neural Eng 4:S143-S156. CrossRef Medline

Becker HF, Polo O, McNamara SG, Berthon-Jones M, Sullivan CE (1996) Effect of different levels of hyperoxia on breathing in healthy subjects. J Appl Physiol 81:1683-1690. Medline

Bell HJ, Haouzi P (2010) The hypoxia-induced facilitation of augmented breaths is suppressed by the common effect of carbonic anhydrase inhibition. Respir Physiol Neurobiol 171:201-211. CrossRef Medline

Bochorishvili G, Stornetta RL, Coates MB, Guyenet PG (2012) Pre- 
Botzinger complex receives glutamatergic innervation from galaninergic and other retrotrapezoid nucleus neurons. J Comp Neurol 520:10471061. CrossRef Medline

Brown DL, Guyenet PG (1985) Electrophysiological study of cardiovascular neurons in the rostral ventrolateral medulla in rats. Circ Res 56:359-369. CrossRef Medline

Chow BY, Han X, Dobry AS, Qian X, Chuong AS, Li M, Henninger MA, Belfort GM, Lin Y, Monahan PE, Boyden ES (2010) High-performance genetically targetable optical neural silencing by light-driven proton pumps. Nature 463:98-102. CrossRef Medline

Chowdhuri S, Sinha P, Pranathiageswaran S, Badr MS (2010) Sustained hyperoxia stabilizes breathing in healthy individuals during NREM sleep. J Appl Physiol 109:1378-1383. CrossRef Medline

Corcoran AE, Richerson GB, Harris MB (2013) Serotonergic mechanisms are necessary for central respiratory chemoresponsiveness in situ. Respir Physiol Neurobiol 186:214-220. CrossRef Medline

Cui Z, Fisher JA, Duffin J (2012) Central-peripheral respiratory chemoreflex interaction in humans. Respir Physiol Neurobiol 180:126-131. CrossRef Medline

Dejours P, Raynoud J, Cuenod CL, Labrousse Y (1955) Instantaneous modifications of ventilation at the beginning and at the cessation of muscular exercise; interpretation. J Physiol (Paris) 47:155-159. Medline

Dempsey JA, Powell FL, Bisgard GE, Blain GM, Poulin MJ, Smith CA (2014) Role of chemoreception in cardiorespiratory acclimatization to, and deacclimatization from, hypoxia. J Appl Physiol 116:858-866. CrossRef Medline

Deng BS, Nakamura A, Zhang W, Yanagisawa M, Fukuda Y, Kuwaki T (2007) Contribution of orexin in hypercapnic chemoreflex: evidence from genetic and pharmacological disruption and supplementation studies in mice. J Appl Physiol 103:1772-1779. CrossRef Medline

Dias MB, Li A, Nattie EE (2009) Antagonism of orexin receptor 1 (OX1R) in the retrotrapezoid nucleus (RTN) inhibits the ventilatory response to hypercapnia predominantly in wakefulness. J Physiol 587:2059-2067. CrossRef Medline

Forster HV, Martino P, Hodges M, Krause K, Bonis J, Davis S, Pan L (2008) The carotid chemoreceptors are a major determinant of ventilatory $\mathrm{CO}_{2}$ sensitivity and of $\mathrm{PaCO}_{2}$ during eupneic breathing. Adv Exp Med Biol 605:322-326. CrossRef Medline

Fortuna MG, Stornetta RL, West GH, Guyenet PG (2009) Activation of the retrotrapezoid nucleus by posterior hypothalamic stimulation. J Physiol 587:5121-5138. CrossRef Medline

Gesell R, Lapides J, Levin M (1940) The interaction of central and peripheral control of breathing. Am J Physiol 130:155-170.

Gestreau C, Heitzmann D, Thomas J, Dubreuil V, Bandulik S, Reichold M, Bendahhou S, Pierson P, Sterner C, Peyronnet-Roux J, Benfriha C, Tegtmeier I, Ehnes H, Georgieff M, Lesage F, Brunet JF, Goridis C, Warth R, Barhanin J (2010) Task2 potassium channels set central respiratory $\mathrm{CO}_{2}$ and $\mathrm{O}_{2}$ sensitivity. Proc Natl Acad Sci U S A 107:2325-2330. CrossRef Medline

Goridis C, Brunet JF (2010) Central chemoreception: lessons from mouse and human genetics. Respir Physiol Neurobiol 173:312-321. CrossRef Medline

Gourine AV, Dale N, Korsak A, Llaudet E, Tian F, Huckstepp R, Spyer KM (2008) Release of ATP and glutamate in the nucleus tractus solitarii mediate pulmonary stretch receptor (Breuer-Hering) reflex pathway. J Physiol 586:3963-3978. CrossRef Medline

Gourine AV, Kasymov V, Marina N, Tang F, Figueiredo MF, Lane S, Teschemacher AG, Spyer KM, Deisseroth K, Kasparov S (2010) Astrocytes control breathing through $\mathrm{pH}$-dependent release of ATP. Science 329:571-575. CrossRef Medline

Guyenet PG, Mulkey DK, Stornetta RL, Bayliss DA (2005) Regulation of ventral surface chemoreceptors by the central respiratory pattern generator. J Neurosci 25:8938-8947. CrossRef Medline

Guyenet PG, Stornetta RL, Bayliss DA (2010) Central respiratory chemoreception. J Comp Neurol 518:3883-3906. CrossRef Medline

Guyenet PG, Stornetta RL, Bochorishvili G, Depuy SD, Burke PG, Abbott SB (2013) Invited review EB 2012: C1 neurons: the body's EMTs. Am J Physiol Regul Integr Comp Physiol 305:R187-R204. CrossRef Medline

Han X, Chow BY, Zhou H, Klapoetke NC, Chuong A, Rajimehr R, Yang A, Baratta MV, Winkle J, Desimone R, Boyden ES (2011) A high-light sensitivity optical neural silencer: development and application to optoge- netic control of non-human primate cortex. Front Syst Neurosci 5:18. CrossRef Medline

Hirooka Y, Polson JW, Potts PD, Dampney RAL (1997) Hypoxia-induced Fos expression in neurons projecting to the pressor region in the rostral ventrolateral medulla. Neurosci 80:1209-1224. CrossRef Medline

Huckstepp RT, Dale N (2011) Redefining the components of central $\mathrm{CO}_{2}$ chemosensitivity: towards a better understanding of mechanism. J Physiol 589:5561-5579. CrossRef Medline

Huckstepp RT, id Bihi R, Eason R, Spyer KM, Dicke N, Willecke K, Marina N, Gourine AV, Dale N (2010) Connexin hemichannel-mediated $\mathrm{CO}_{2}-$ dependent release of ATP in the medulla oblongata contributes to central respiratory chemosensitivity. J Physiol 588:3901-3920. CrossRef Medline

Hwang DY, Carlezon WA Jr, Isacson O, Kim KS (2001) A high-efficiency synthetic promoter that drives transgene expression selectively in noradrenergic neurons. Hum Gene Ther 12:1731-1740. CrossRef Medline

Iceman KE, Richerson GB, Harris MB (2013) Medullary serotonin neurons are $\mathrm{CO}_{2}$-sensitive in situ. J Neurophysiol 110:2536-2544. CrossRef Medline

Javaheri S, Dempsey JA (2013) Central sleep apnea. Compr Physiol 3:141163. CrossRef Medline

Jespersen B, Knupp L, Northcott CA (2012) Femoral arterial and venous catheterization for blood sampling, drug administration and conscious blood pressure and heart rate measurements. J Vis Exp 24:3496. CrossRef Medline

Koshiya N, Guyenet PG (1996) NTS neurons with carotid chemoreceptor inputs arborize in the rostral ventrolateral medulla. Am J Physiol Regul Integr Comp Physiol 270:R1273-R1278. Medline

Kumar P, Prabhakar NR (2012) Peripheral chemoreceptors: function and plasticity of the carotid body. Compr Physiol 2:141-219. CrossRef Medline

Lazarenko RM, Milner TA, Depuy SD, Stornetta RL, West GH, Kievits JA, Bayliss DA, Guyenet PG (2009) Acid sensitivity and ultrastructure of the retrotrapezoid nucleus in Phox2b-EGFP transgenic mice. J Comp Neurol 517:69-86. CrossRef Medline

Li A, Randall M, Nattie EE (1999) CO(2) microdialysis in retrotrapezoid nucleus of the rat increases breathing in wakefulness but not in sleep. J Appl Physiol 87:910-919. Medline

Li A, Zhou S, Nattie E (2006) Simultaneous inhibition of caudal medullary raphe and retrotrapezoid nucleus decreases breathing and the $\mathrm{CO}_{2}$ response in conscious rats. J Physiol 577:307-318. CrossRef Medline

Li N, Li A, Nattie E (2013) Focal microdialysis of CO(2) in the perifornicalhypothalamic area increases ventilation during wakefulness but not NREM sleep. Respir Physiol Neurobiol 185:349-355. CrossRef Medline

Loeschcke HH (1982) Central chemosensitivity and the reaction theory. J Physiol 332:1-24. Medline

Madden CJ, Sved AF (2003) Cardiovascular regulation after destruction of the $\mathrm{C} 1$ cell group of the rostral ventrolateral medulla in rats. Am J Physiol Heart Circ Physiol 285:H2734-H2748. CrossRef Medline

Marina N, Abdala AP, Trapp S, Li A, Nattie EE, Hewinson J, Smith JC, Paton JF, Gourine AV (2010) Essential role of Phox2b-expressing ventrolateral brainstem neurons in the chemosensory control of inspiration and expiration. J Neurosci 30:12466-12473. CrossRef Medline

Mattis J, Tye KM, Ferenczi EA, Ramakrishnan C, O'Shea DJ, Prakash R, Gunaydin LA, Hyun M, Fenno LE, Gradinaru V, Yizhar O, Deisseroth K (2012) Principles for applying optogenetic tools derived from direct comparative analysis of microbial opsins. Nat Methods 9:159-172. CrossRef Medline

McBryde FD, Abdala AP, Hendy EB, Pijacka W, Marvar P, Moraes DJ, Sobotka PA, Paton JF (2013) The carotid body as a putative therapeutic target for the treatment of neurogenic hypertension. Nat Commun 4:2395. CrossRef Medline

Mulkey DK, Wenker IC (2011) Astrocyte chemoreceptors: mechanisms of $\mathrm{H}^{+}$sensing by astrocytes in the retrotrapezoid nucleus and their possible contribution to respiratory drive. Exp Physiol 96:400-406. CrossRef Medline

Mulkey DK, Stornetta RL, Weston MC, Simmons JR, Parker A, Bayliss DA, Guyenet PG (2004) Respiratory control by ventral surface chemoreceptor neurons in rats. Nat Neurosci 7:1360-1369. CrossRef Medline

Nattie E (2011) Julius H. Comroe, Jr., distinguished lecture: central chemoreception: then and now. J Appl Physiol 110:1-8. CrossRef Medline

Olson EB Jr, Vidruk EH, Dempsey JA (1988) Carotid body excision signifi- 
cantly changes ventilatory control in awake rats. J Appl Physiol 64:666671. CrossRef Medline

Pappenheimer JR (1977) Sleep and respiration of rats during hypoxia. J Physiol 266:191-207. Medline

Pattyn A, Morin X, Cremer H, Goridis C, Brunet JF (1999) The homeobox gene Phox $2 \mathrm{~b}$ is essential for the development of autonomic neural crest derivatives. Nature 399:366-370. CrossRef Medline

Paxinos G, Watson C (2005) The rat brain in stereotaxic coordinates, Ed 5. San Diego: Elsevier Academic.

Peña F, García O (2006) Breathing generation and potential pharmacotherapeutic approaches to central respiratory disorders. Curr Med Chem 13: 2681-2693. CrossRef Medline

Phillipson EA, Sullivan CE, Read DJ, Murphy E, Kozar LF (1978) Ventilatory and waking responses to hypoxia in sleeping dogs. J Appl Physiol 44:512-520. Medline

Ramanantsoa N, Hirsch MR, Thoby-Brisson M, Dubreuil V, Bouvier J, Ruffault PL, Matrot B, Fortin G, Brunet JF, Gallego J, Goridis C (2011) Breathing without $\mathrm{CO}_{2}$ chemosensitivity in conditional Phox $2 \mathrm{~b}$ mutants. J Neurosci 31:12880-12888. CrossRef Medline

Sato M, Severinghaus JW, Basbaum AI (1992) Medullary $\mathrm{CO}_{2}$ chemoreceptor neuron identification by c-fos immunocytochemistry. J Appl Physiol 73:96-100. Medline

Schultz HD, Marcus NJ, Del Rio R (2013) Role of the carotid body in the pathophysiology of heart failure. Curr Hypertens Rep 15:356-362. CrossRef Medline

Sharma B, McSharry D, Malhotra A (2011) Sleep disordered breathing in patients with heart failure: pathophysiology and management. Curr Treat Options Cardiovasc Med 13:506-516. CrossRef Medline

Smith CA, Rodman JR, Chenuel BJ, Henderson KS, Dempsey JA (2006) Response time and sensitivity of the ventilatory response to $\mathrm{CO}_{2}$ in unanesthetized intact dogs: central vs peripheral chemoreceptors. J Appl Physiol 100:13-19. CrossRef Medline

Smith CA, Forster HV, Blain GM, Dempsey JA (2010) An interdependent model of central/peripheral chemoreception: evidence and implications for ventilatory control. Respir Physiol Neurobiol 173:288-297. CrossRef Medline

Smith JC, Morrison DE, Ellenberger HH, Otto MR, Feldman JL (1989) Brainstem projections to the major respiratory neuron populations in the medulla of the cat. J Comp Neurol 281:69-96. CrossRef Medline

Song G, Xu H, Wang H, Macdonald SM, Poon CS (2011) Hypoxia-excited neurons in NTS send axonal projections to Kolliker-Fuse/parabrachial complex in dorsolateral pons. Neuroscience 175:145-153. CrossRef Medline
Sparta DR, Stamatakis AM, Phillips JL, Hovelsø N, van Zessen R, Stuber GD (2012) Construction of implantable optical fibers for long-term optogenetic manipulation of neural circuits. Nat Protoc 7:12-23. CrossRef Medline

Stornetta RL, Moreira TS, Takakura AC, Kang BJ, Chang DA, West GH, Brunet JF, Mulkey DK, Bayliss DA, Guyenet PG (2006) Expression of Phox $2 \mathrm{~b}$ by brainstem neurons involved in chemosensory integration in the adult rat. J Neurosci 26:10305-10314. CrossRef Medline

Sun MK, Reis DJ (1994) Hypoxia selectively excites vasomotor neurons of rostral ventrolateral medulla in rats. Am J Physiol Regul Integr Comp Physiol 266:R245-R256. Medline

Sun MK, Reis DJ (1996) Medullary vasomotor activity and hypoxic sympathoexcitation in pentobarbital-anesthetized rats. Am J Physiol Regul Integr Comp Physiol 270:R348-R355. Medline

Swenson ER (2014) Carbonic anhydrase inhibitors and high altitude illnesses. Subcell Biochem 75:361-386. CrossRef Medline

Takakura AC, Moreira TS, Colombari E, West GH, Stornetta RL, Guyenet PG (2006) Peripheral chemoreceptor inputs to retrotrapezoid nucleus (RTN) $\mathrm{CO}_{2}$-sensitive neurons in rats. J Physiol 572:503-523. CrossRef Medline

Takakura AC, Moreira TS, De Paula PM, Menani JV, Colombari E (2013) Control of breathing and blood pressure by parafacial neurons in conscious rats. Exp Physiol 98:304-315. CrossRef Medline

Teppema LJ, Veening JG, Kranenburg A, Dahan A, Berkenbosch A, Olievier C (1997) Expression of $c$-fos in the rat brainstem after exposure to hypoxia and to normoxic and hyperoxic hypercapnia. J Comp Neurol 388:169190. CrossRef Medline

Wang S, Shi Y, Shu S, Guyenet PG, Bayliss DA (2013a) Phox2b-expressing retrotrapezoid neurons are intrinsically responsive to acidification and $\mathrm{CO}_{2}$. J Neurosci 33:7756-7761. CrossRef Medline

Wang S, Benamer N, Zanella S, Kumar NN, Shi Y, Bévengut M, Penton D, Guyenet PG, Lesage F, Gestreau C, Barhanin J, Bayliss DA (2013b) TASK-2 channels contribute to $\mathrm{pH}$ sensitivity of retrotrapezoid nucleus chemoreceptor neurons. J Neurosci 33:16033-16044. CrossRef Medline

Weese-Mayer DE, Berry-Kravis EM, Ceccherini I, Keens TG, Loghmanee DA, Trang H (2010) An official ATS clinical policy statement: congenital central hypoventilation syndrome: genetic basis, diagnosis, and management. Am J Respir Crit Care Med 181:626-644. CrossRef Medline

Williams RH, Jensen LT, Verkhratsky A, Fugger L, Burdakov D (2007) Control of hypothalamic orexin neurons by acid and $\mathrm{CO}_{2}$. Proc Natl Acad Sci U S A 104:10685-10690. CrossRef Medline 